\title{
COMBINAÇÃO ENTRE FONTES PROTÉICAS E ENERGÉTICAS COM DIFERENTES DEGRADABILIDADES RUMINAIS PARA VACAS EM LACTAÇÃO
}

\section{Éberson de CASTilho Barnabé}

Engenheiro Agrônomo

Orientador : Prof. Dr. FLÁVIO AUGUSTO PORTELA SANTOS

Dissertação apresentada à Escola Superior de Agricultura "Luiz de Queiroz", Universidade de São Paulo, para obtenção do título de Mestre em Agronomia, Área de Concentração: Ciência Animal e Pastagens.

PIRACICABA

Estado de São Paulo - Brasil

Novembro - 2001 


\section{Dados Internacionais de Catalogação na Publicação (CIP) DIVISÃO DE BIBLIOTECA E DOCUMENTAÇÃO - ESALQ/USP}

Barnabé, Éberson de Castilho

Combinação entre fontes protéicas e energéticas com diferentes degradabilidades ruminais para vacas em lactação / Éberson de Castilho Barnabé. - - Piracicaba, 2001.

$56 \mathrm{p}$.

Dissertação (mestrado) - - Escola Superior de Agricultura Luiz de Queiroz, 2001. Bibliografia.

1. Degradação 2. Dieta animal 3. Digestibilidade 4. Fonte protéica 5. Rúmen animal 6. Vaca leiteira I. Título

CDD 636.214

"Permitida a copia total ou parcial deste documento. desde que citada a fonte -0 autor? 


\begin{abstract}
À minha mãe, Rosimeire e
Ao meu pai, Valdemar

Pela dedicação aos seus filhos e pelo incentivo, apoio, amizade e carinho que sempre demonstraram.
\end{abstract}

\title{
DEDICO
}




\section{AGRADECIMENTOS}

À Escola Superior de Agricultura Luiz de Queiroz (USP) e em especial ao Departamento de Produção Animal - Setor de Ruminantes, pela oportunidade de realização deste curso.

Ao Prof. Dr. Flávio Augusto Portela Santos pela orientação segura, pelos ensinamentos valiosos, pela amizade, confiança e exemplo de dedicação profissional.

À Fundação de Amparo à Pesquisa do Estado de São Paulo (FAPESP), pela concessão da bolsa de estudos durante o transcorrer do curso.

Ao Prof. Dr. José Manuel Corrêa de Simas, pelas sugestões, colaboração e orientação na execução deste trabalho, pela amizade e exemplo profissional.

Aos demais professores do Departamento de Produção Animal, pelos ensinamentos, cordialidade e pela amizade.

Aos amigos e colegas de curso Carla Maris de Bittar Nussio, Hugo Imaizumi, Sérgio de Oliveira Juchem, Miguel da Rocha Cavalcanti (Ribamar) e Flávio Castro, pela amizade e pelo auxílio na condução do experimento de campo.

Ao funcionário do Laboratório de Bromatologia do Departamento de Produção Animal Carlos César Alves, pela amizade, paciência, ensinamentos e pela colaboração nas análises laboratoriais.

Aos demais funcionários e colegas do curso de pós-graduação, pela amizade, pela ajuda e pela agradável convivência.

À ESALQ - Escola Superior de Agricultura Luiz de Queiroz (USP), pela minha formação acadêmica.

Aos meus queridos pais Rosimeire e Valdemar e minhas irmãs Enádija e Élida, pela confiança e grande incentivo para execução deste trabalho.

Às pessoas que, direta ou indiretamente, contribuiram para a realização deste trabalho. 


\section{SUMÁRIO}

Página

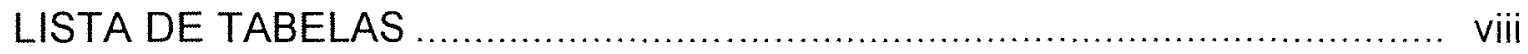

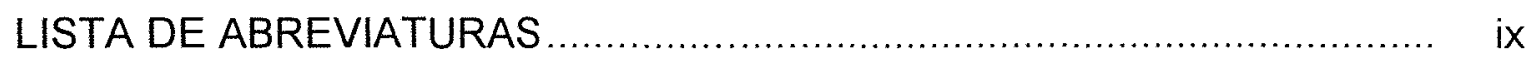

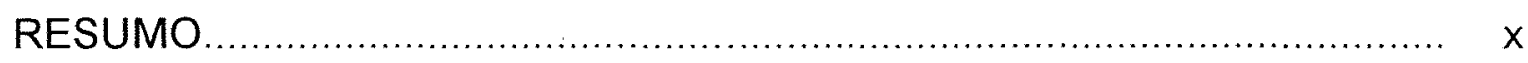

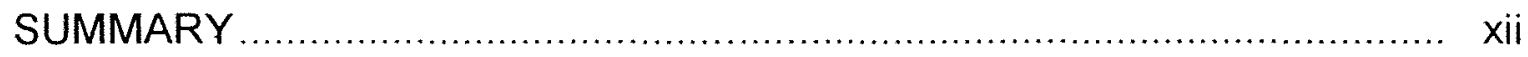

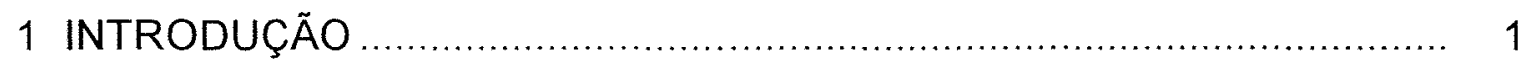

2 REVISÃO DE LITERATURA .................................................... 4

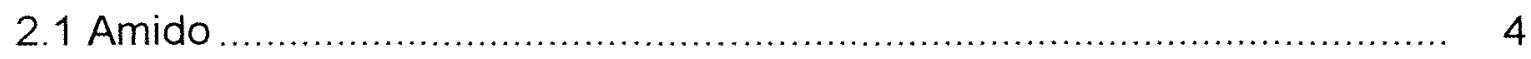

2.1.1 Caracterização das fontes de amido .............................................. 4

2.1.2 Processamento do grão de milho .............................................. 5

2.2 Proteína na nutrição de ruminantes .................................................... 7

2.2.1 Uso de soja na nutrição de ruminantes .......................................... 10

2.3 Síntese de proteína microbiana no rúmen ........................................ 12

2.3.1 Fatores que afetam a síntese microbiana .................................. 14

2.4 Sincronismo entre energia e proteína no rúmen ............................... 15

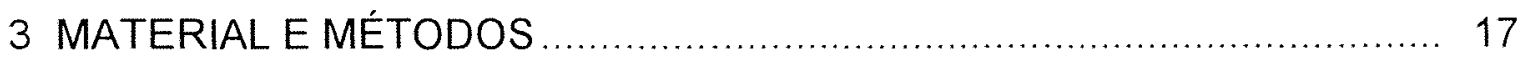

3.1 Animais e instalações experimentais .......................................... 17

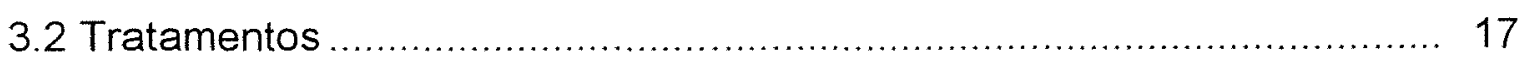

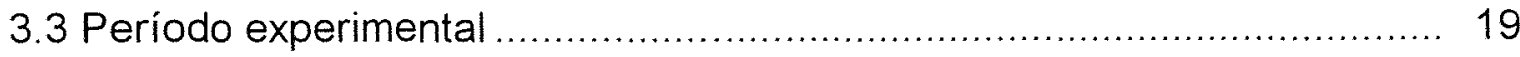


3.4 Administração de Iterbio (marcador externo) ................................. 19

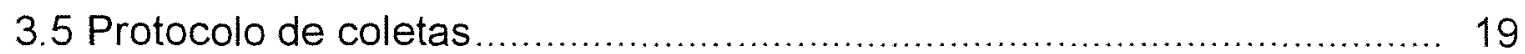

3.5.1 Pesagem e amostragem do alimento oferecido e recusado ............... 19

3.5.2 Produção e composição de leite ................................................... 20

3.5.3 Coleta de bolo alimentar do duodeno......................................... 20

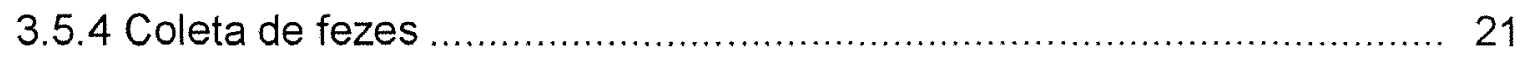

3.5.5 Coleta de dados para determinação dos parâmetros ruminais ............ 21

3.5.6 Coleta de dados para determinação dos parâmetros sangüineos ........ 21

3.6 Preparo das amostras e análises laboratoriais................................. 22

3.6.1 Análises químico-bromatológicas............................................... 22

3.6.2 Análise de glicose e uréia plasmática ......................................... 22

3.6.3 Análise de amônia e AGV no fluido ruminal ..................................... 22

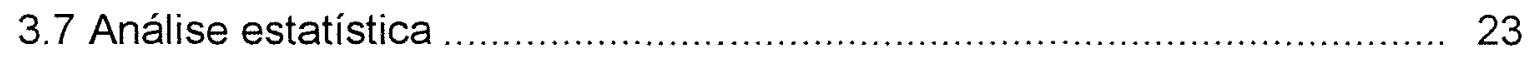

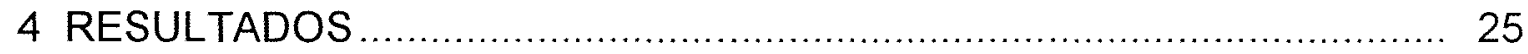

4.1 Consumo de matéria seca .............................................................. 25

4.2 Produção e composição do leite ....................................................... 25

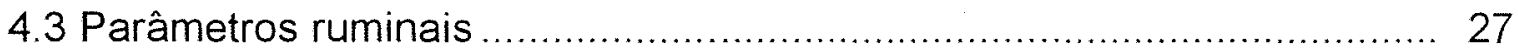

4.3.1 Concentração de nitrogênio amoniacal no rúmen ........................... 27

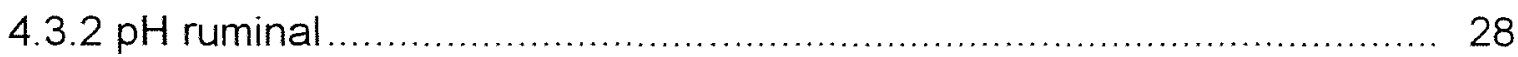

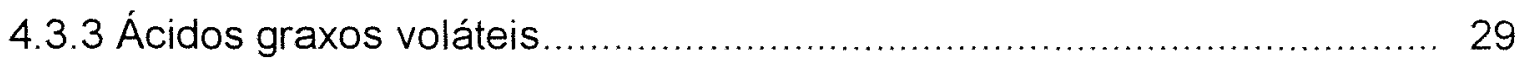

4.3.3.1 Ácidos graxos voláteis totais ................................................. 29

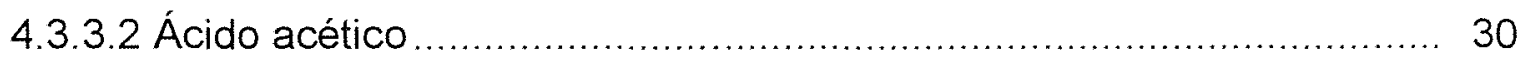

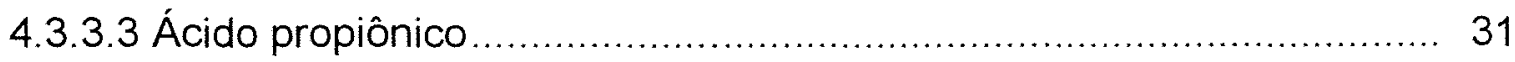

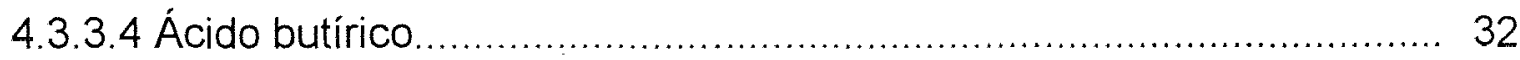


4.3.3.5 Relação acetato:propionato............................................... 33

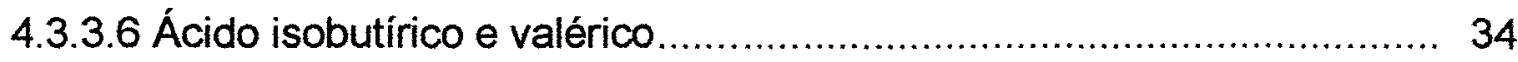

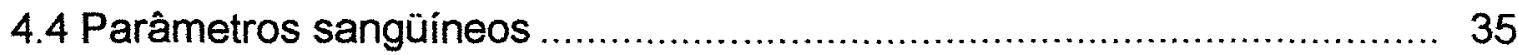

4.4.1 Glicose plasmática ................................................................. 35

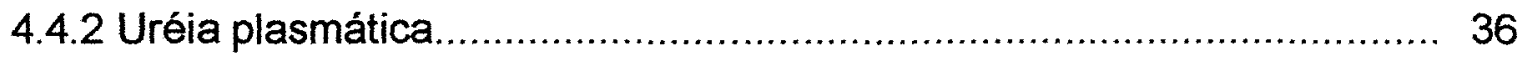

4.5 Digestibilidade de nutrientes .......................................................... 37

4.6 Fluxo duodenal de nutrientes ................................................... 38

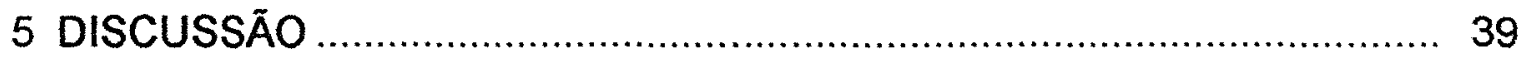

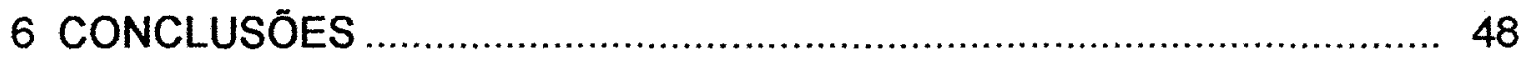

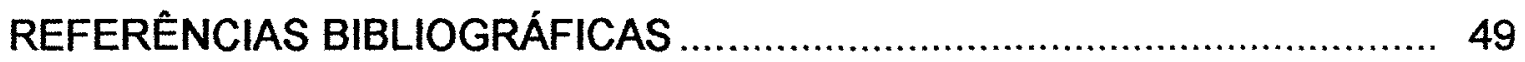




\section{LISTA DE TABELAS}

Página

1 Proporção dos ingredientes e composição média nutricional das dietas experimentais.

2 Resumo esquemático da análise de variância para consumo de MS, eficiência alimentar, produção e composição do leite e digestibilidade dos nutrientes.

3 Análise de variância para os parâmetros ruminais. ............................. 24

4 Análise de variância para os parâmetros sanguíneos. ......................... 24

5 Valores médios de consumo de MS, produção e composição do leite... 26

6 Valores de quadrados mínimos da concentração de amônia ruminal (mg/dL).

7 Valores de quadrados mínimos do $\mathrm{pH}$ ruminal.

28

8 Valores de quadrados mínimos da concentração total de AGV no rúmen $(\mathrm{mM})$.

9 Valores de quadrados mínimos da concentração (mM) de acetato no rúmen.

10 Valores de quadrados mínimos da concentração $(\mathrm{mM})$ de propionato no rúmen.

11 Valores de quadrados mínimos da concentração $(\mathrm{mM})$ de butirato no rúmen.

12 Valores de quadrados mínimos da relação acetato:propionato produzidos no rúmen.

13 Valores de quadrados minimos da concentração de isobutirato e valerato no rúmen.

14 Valores médios da concentração de glicose plasmática (mg/dL) . ........ 35

15 Valores médios da concentração de uréia plasmática $(\mathrm{mg} \mathrm{N} / \mathrm{dL})$.......... 36

16 Digestibilidade dos nutrientes (\%MS) ............................................ 37

17 Fluxo de nutrientes para o duodeno (g/d) ...................................... 38 


\title{
LISTA DE ABREVIATURAS
}

\author{
$A A$ - aminoácidos \\ AAE - aminoácidos essenciais \\ AGV - ácidos graxos voláteis \\ EE - extrato etéreo \\ $E L_{L}$ - energia líquida de lactação \\ FDA - fibra em detergente ácido \\ FDN - fibra em detergente neutro \\ FE - fonte de energia \\ FP - fonte de proteína \\ MF - milfho floculado \\ MM - matéria mineral \\ MMG - milho moido grosso \\ MO - matéria orgânica \\ MS - matéria seca \\ NDT - nutrientes digestiveis totais \\ $\mathrm{N}-\mathrm{NH}_{3}$ - nitrogênio amoniacal \\ NNP - nitrogênio não protéico \\ PB - proteína bruta \\ PDR - proteína degradável no rúmen \\ PM - proteína microbiana \\ PNDR - proteína não degradável no rúmen \\ SC - grão de soja cru \\ ST - grão de soja tostado
}




\title{
COMBINAÇÃO ENTRE FONTES PROTÉICAS E ENERGÉTICAS COM DIFERENTES DEGRADABILIDADES RUMINAIS PARA VACAS EM LACTAÇÃO
}

\author{
Autor: ÉBERSON DE CASTILHO BARNABÉ \\ Orientador: Prof. Dr. FLÁVIO AUGUSTO PORTELA SANTOS
}

\section{RESUMO}

Avaliou-se quatro vacas Holandesas multíparas em um delineamento do tipo Quadrado Latino $4 \times 4$. Os animais estudados eram providos de cânulas no rúmen e duodeno e possuiam produção média de leite de $23 \mathrm{~kg} / \mathrm{dia}$ e 130 dias de lactação. Através de um arrranjo fatorial de tratamentos, objetivou-se determinar o efeito da tentativa de sincronização ruminal entre duas fontes de proteína (grão de soja cru ou tostado) e de amido (milho moído fino ou floculado a $360 \mathrm{~g} / \mathrm{L})$. Os tratamentos não afetaram $(P>0,05)$ o consumo de matéria seca, porém animais recebendo milho floculado tenderam a aumentar $(P=0,12)$ a produção de leite e diminuir $(P=0,12)$ o teor de gordura no leite. A tostagem do grão de soja não levou $(P>0,05)$ a melhor desempenho lactacional dos animais. $\mathrm{O} \mathrm{pH}$ ruminal não foi afetado $(P>0,05)$ pelos tratamentos. Tanto a tostagem do grão de soja quanto a floculação do milho diminuíram $(P<0,01)$ as concentrações ruminais de nitrogênio amoniacal. Animais recebendo milho floculado tenderam $(P=0,102)$ a apresentar maiores concentrações totais de AGV. As digestibilidades ruminal e no trato total dos nutrientes não foram afetados $(P>0,05)$ pelos tratamentos, com exceção de uma tendência para 
maior $(P=0,06)$ digestibilidade ruminal de amido quando se forneceu soja crua, ao invés de soja tostada. 


\title{
PROTEIN AND ENERGY SOURCES WITH VARYING RUMINAL DEGRADABILITIES FOR LACTATING DAIRY COWS
}

\author{
Author: ÉBERSON DE CASTILHO BARNABÉ \\ Adviser: Prof. Dr. FLÁVIO AUGUSTO PORTELA SANTOS
}

\section{SUMMARY}

Four mid lactating (130 DIM) Holstein cows, canulated in the rumen and duodenum, were used in a $4 \times 4$ Latin Square design. A $2 \times 2$ factorial arrangement was adopted to study the effect of combining two protein (raw vs. roasted soybeans) with two starch sources (coarsely ground vs. steam-flaked corn $360 \mathrm{~g} / \mathrm{L})$. Intake of dry matter was not affected $(P>0.05)$ by treatments. Flaking of corn tended to increase $(P=0.122)$ milk yield and to decrease $(P=0.12)$ milk fat content, but not $(P>0.05)$ milk fat yield. Roasting of soybean did not improve $(P>0.05)$ lactational performance of mid lactating cows. Rumen $\mathrm{pH}$ was not affected $(\mathrm{P}>0.05)$ by treatments. Both roasting of soybeans and flaking of corn decreased $(P<0.01)$ rumen ammonia nitrogen. Flaking of corn tended to increase $(P=0.102)$ total VFA molar concentration. Nutrient digestibilities in the rumen and in the total tract were not affected $(P>0.05)$ by treatments, except for a tendency of higher $(P=0.06)$ rumen starch digestibility with raw vs, roasted soybean. 


\section{INTRODUÇÃO}

A exigência nutricional de vacas leiteiras de alta produção é considerável e os dois fatores nutricionais mais limitantes são normalmente, energia e proteína.

Como a proteína é um dos ingredientes de custo mais elevado na dieta dos animais, a eficiência de utilização da mesma tem sido o tema de vários trabalhos conduzidos nos últimos 15 anos, com o intuito de ampliar nossos conhecimentos referentes à relação entre proteína degradável e proteína não degradável no rúmen (PNDR), adequação de proteína metabolizável, perfil de aminoácidos na proteína metabolizável e ainda a interação (sincronização) entre fontes de energia e fontes protéicas (Santos et al., 1998).

Durante a década de 80 e início da de 90 , difundiu-se a idéia de que seria vantajoso para ruminantes, se a degradação da proteína e do amido ocorressem preferencialmente no intestino delgado ao invés de ocorrer no rúmen. Supunha-se que evitando as perdas no processo fermentativo, maiores quantidades de energia e proteína seriam economizadas, resultando em melhora no desempenho animal. Estes conceitos foram baseados em cálculos teóricos, em resultados positivos encontrados em ensaios que obtiveram aumento na produção de leite através da infusão de caseína diretamente no abomaso ou no intestino delgado, e em estudos "in vitro" que sugeriam a maximização de sintese de proteína microbiana com niveis muito baixos de amônia ruminal (Santos et al., 1998; Theurer et al., 1999). 
Portanto, apesar de não estar bem conhecida a complexa relação entre os requerimentos de $\mathrm{N}$ e energia para os microrganismos do rúmen e para a vaca, foi preconizado nos últimos anos a suplementação de proteína $\mathrm{e}$ amido resistentes à degradação ruminal, acreditando que o uso desta técnica aumentaria o aporte de aminoácidos essenciais (AAE) e de glicose para o intestino delgado e consequentemente para a glândula mamaria, refletindo em aumento de produção de leite. Entretanto, em recentes revisões sobre o assunto, Santos et al. (1998), Santos \& Huber (1996), Huntington (1997) e Theurer et al. (1995; 1999) mostraram que a teoria da nutrição "bypass" apresenta inúmeros pontos falhos.

$\mathrm{Na}$ tentativa de se estudar $\mathrm{o}$ assunto, diversos ensaios de metabolismo e de produção vem sendo realizados tanto com bovinos de corte como de leite em diversas universidades de paises desenvolvidos. Segundo Santos et al. (1998), o uso de proteína protegida se justifica após a máxima exploração da sintese microbiana no rúmen, com o uso de fontes de PNDR de boa qualidade, capazes de complementar a proteína microbiana em termos de $A A E$, com ênfase em uma adequada proporção de lisina e metionina na proteína metabolizável no intestino delgado, conforme sugerido por Sloan et al. (1999). O processamento de milho e sorgo para aumentar a degradabilidade ruminal do amido resulta em desempenho superior em ruminantes (Santos, 1996; Theurer et al., 1999). No entanto, ainda é necessária a realização de pesquisas com vacas de alta produção, a fim de se identificar combinações de fontes protéicas e energéticas que sincronizem a disponibilidade ruminal de energia e de $\mathrm{N}$ para otimizar a sintese de proteina microbiana, fluxo de nutrientes para o intestino delgado, como também para maximizar a produção de ácidos graxos voláteis (AGV) no rúmen.

O objetivo deste trabalho foi estudar a tentativa de sincronização da degradação ruminal de proteina e energia através da combinação entre fontes protéicas (SC $\times \mathrm{ST}$ ) e fontes de amido (MMG $\times$ MF $360 \mathrm{~g} / \mathrm{L}$ ) com níveis 
variáveis de degradabilidade ruminal em dietas para vacas leiteiras de alta produção.

Os parâmetros avaliados estão listados a seguir:

$\checkmark$ ingestão de matéria seca;

$\checkmark$ produção e composição do leite;

$\checkmark \mathrm{pH}$, ácidos graxos voláteis e concentração de amônia no fluido ruminal;

$\checkmark$ digestibilidade dos nutrientes no rúmen, pós rúmen e no trato digestivo total;

$\checkmark$ fluxo de aminoácidos para o duodeno

$\checkmark$ concentração plasmática de uréia e glicose. 


\section{REVISÃO DE LITERATURA}

\subsection{Amido}

\subsubsection{Caracterização das fontes de amido}

Diversos trabalhos de pesquisa vêm sendo conduzidos nas últimas décadas com o objetivo de maximizar a eficiência de utilização de carboidratos não estruturais, especialmente o amido, para vacas leiteiras.

O amido representa 70 a $80 \%$ da matéria seca da maioria dos cereais como milho, sorgo, cevada, trigo e aveia e é normalmente a fonte primária de energia em dietas de ruminantes com o objetivo de se obter altos desempenhos (Rooney \& Pflugfelder, 1986). Dietas usadas comercialmente para vacas de alta produção contêm em torno de 25 a $35 \%$ de amido na matéria seca (Theurer et al., 1999). Sendo assim, a utilização eficiente do amido é fundamental para se maximizar a produção animal.

O amido é o principal substrato para a síntese de ácidos graxos voláteis (AGV) no rúmen, os quais representam a fonte majoritária de energia para os ruminantes. A fermentação ruminal de amido também se constitui na principal fonte geradora de propionato, o precursor de maior importância para a síntese de glicose no fígado. Além disso, o amido também é a fonte de energia mais importante para o crescimento microbiano no rúmen. Desta forma, os suprimentos de energia, glicose e aminoácidos para a glândula mamaria são afetados de forma expressiva em função da eficiência com que o amido é utilizado pelo animal e pelo sítio de digestão desse amido no trato digestivo (Nocek \& Tamminga, 1991; Theurer et al., 1999). 
O amido existe na forma de grãos altamente organizados, nos quais amilose e amilopectina são mantidas juntas por pontes de hidrogênio. A amilose é um polímero linear de unidades de d-glucose unidos por ligações to tipo alfa1,4 , enquanto a amilopectina é um polímero ramificado, sendo o mais abundante componente do amido. A amilopectina corresponde a cerca de 70 a $80 \%$ da maioria dos amidos. Os grãos de amido são pseudocristais que têm regiões organizadas (cristalina) e não organizadas (amorfa). A amilopectina é primariamente cristalina e é resistente à entrada de água e degradação enzimática. A região amorfa do amido é rica em amilose e menos densa que a cristalina, permitindo um livre movimento da água (Rooney \& Pflugfelder, 1986).

$O$ ataque das amilases aos grãos de amido é iniciado na região amorfa, enquanto que a hidrólise da região cristalina ocorre mais vagarosamente (Rooney \& Pflugfelder, 1986). A relação amilose:amilopectina influencia a degradabilidade do amido. Outros fatores que afetam a utilização de amido pelos animais são as matrizes de proteína e os corpos protéicos. Os corpos protéicos do milho e sorgo são de baixa degradabilidade, retardando a hidrólise enzimática do amido devido a uma associação muito forte entre os grãos de amido e os corpos protéicos (Delfino, 1986). Os grãos de amido são envoltos por matrizes de proteína que rodeiam o endosperma de todos os grãos e afetam a digestibilidade do amido com elas associado. As digestibilidades do amido do milho e do sorgo são menores do que as do trigo, cevada e aveia, devido à maior presença desta matriz protéica (Rooney \& Pflugfelder, 1986).

\subsubsection{Processamento do grão de milho}

O milho e o sorgo são alimentos utilizados principalmente pela energia proveniente do amido e diferentes formas de processamento podem ser aplicadas para maximizar a sua eficiência. Os métodos de processamento estão geralmente associados com a melhoria na eficiência da utilização dos 
grãos e podem ser divididos em processos físicos e químicos (Nocek \& Tamminga, 1991).

O processamento físico usualmente consiste na quebra, moagem, trituração, ou peletização de grãos secos. Modificações físico-químicas envolvem a aplicação de calor e água, que hidrata e incha as estruturas amorfas e cristalinas dos grãos de amido. Estas alterações na estrutura aumentam a digestão amilolítica por ambas enzimas, produzidas por microrganismos ruminais e pelo pâncreas do ruminante.

O grão inteiro com o pericarpo intacto é altamente resistente à digestão por bactérias ruminais por não permitir a adesão das mesmas (McAllister et al. 1994; Beauchemin et al., 1994). O processamento com umidade e vapor também quebra as matrizes e corpos protéicos que dificultam a digestão do amido, permitindo um maior acesso à digestão enzimática (Nocek \& Tamminga, 1991). A reconstituição, que consiste no aumento de umidade até $30 \%$ e armazenagem anaeróbia do grão por 2-3 semanas antes da moagem e utilização, também melhora a utilização do amido por ruminantes. A maioria dos métodos de processamento aumenta a digestibilidade de amido no rúmen, o que usualmente aumenta a digestibilidade de amido no intestino delgado (Owens \& Goetsch, 1986).

A floculação do milho ou sorgo consiste da aplicação de vapor por 30 a 40 minutos sobre o grão, que então absorve a água e incha. Tem início o processo de gelatinização do amido, aumentando sua digestibilidade. Então os grãos são passados através de rolos, ocorrendo o processo de floculação, onde a área superficial é aumentada significativamente e a matriz protéica é quebrada. O resultado final é o aumento da digestibilidade do amido (Theurer et al., 1995).

Até o início da década de 90 , acreditava-se que a produção de leite seria favorecida caso o amido da dieta fosse digerido preferencialmente no intestino delgado, minimizando assim as perdas energéticas resultantes da 
fermentação ruminal e aumentando o aporte de glicose para a glândula mamária (Owens et al., 1986; Nocek \& Tamminga, 1991).

Trabalhos conduzidos na Universidade do Arizona têm mostrando de forma consistente que quando a degradabilidade ruminal do amido é aumentada através da floculação do milho ou sorgo, a produção de leite ( 5 a $10 \%$ ) e de proteína do leite (12 a 16\%) são incrementadas devido a uma maior disponibilidade de energia e proteína para a glândula mamária (Theurer et al., 1993; 1995; 1999).

Os dados de pesquisa com gado de corte e com gado leiteiro, gerados principalmente na década de 90, levaram Huntington (1997) a afirmar de forma conclusiva que a eficiência de utilização do amido é maior quando digerido preferencialmente no rúmen. Isto se deve à maior produção de AGV no rúmen e consequente maior aporte de energia para o animal, maior síntese de glicose hepática devido à maior disponibilidade de propionato, maior síntese de proteína microbiana no rúmen, além da intensa utilização pelos tecidos viscerais (como trato digestivo, pâncreas, baço e gordura) da glicose gerada a partir da digestão intestinal do amido.

\subsection{Proteína na nutrição de ruminantes}

O processo digestivo dos ruminantes é bastante complexo, apresentando características peculiares em relação à suplementação protéica. A proteína absorvida pelo animal para atender suas funções provém do "pool" presente no intestino delgado e é resultado da soma da proteína microbiana sintetizada no rúmen, da proteína da dieta que escapou da degradação ruminal e da proteína endógena (Santos et al., 1998; NRC, 2001).

Em 1985, o NRC propôs um novo modelo para cálculo de rações baseado em proteína absorvida, substituindo a até então utilizada proteína bruta (PB). A exigência protéica do animal foi dividida em proteina degradável no rúmen (PDR), a qual deve suprir as exigências dos microrganismos, e 
proteína não degradável no rúmen (PNDR), a qual deve complementar a proteina microbiana que chega ao intestino delgado, a fim de suprir as exigências protéicas da vaca leiteira

Após a publicação do NRC (1985), um grande número de trabalhos de pesquisa passaram a ser conduzidos com o intuito de se determinar a real exigência em PDR e PNDR em dietas para vacas de alta produção. A maioria dos trabalhos teve seu enfoque voltado para o incremento do teor de PNDR nas dietas através da substituição de fontes convencionais como o farelo de soja por fontes ricas em PNDR, como farinha de carne, farinha de sangue, farinha de peixe, farelo de glúten de milho, farelo de soja tratado química ou fisicamente e ST, entre outros. Criou-se uma expectativa de que a inclusão de fontes ricas em PNDR em dietas para vacas em lactação pudesse resultar em grandes incrementos na produção de leite.

Entretanto, Santos et al. (1998) revisaram a literatura publicada entre 1985 a 1997, onde o farelo de soja foi substituído por fontes ricas em PNDR em dietas para vacas em lactação e relataram que em apenas $17 \%$ dos casos houve efeito positivo dessa substituição. Na grande maioria dos trabalhos, não houve efeito da adição de fontes ricas em PNDR e, em alguns estudos, observou-se efeito negativo. Os autores postularam que os resultados frustrantes verificados com o uso de fontes ricas em PNDR se deveu a vários fatores, principalmente: a) redução da síntese de proteína microbiana por deficiência de PDR na dieta; b) ausência de aumento no fluxo de proteína total para o intestino, em função da menor síntese de proteína microbiana anular o benefício de maior fluxo de proteína da dieta; c) perfil de aminoácidos essenciais inadequado da fonte de PNDR.

Relativo à nutrição protéica de vacas leiteiras, o final da década de 90 foi marcado por um grande interesse da comunidade científica em se estudar as exigências em aminoácidos para esses animais. Dois grupos de pesquisadores têm se destacado nesta área, o grupo americano liderado pelo Dr. Schwab e o grupo francês liderado pelo Dr. Rulquin. 
Ambos os grupos têm mostrado resultados concordantes, enfatizando a importância do ajuste de lisina e de metionina na dieta, por serem estes os dois aminoácidos mais limitantes para a produção de leite (Schwab, 1994; Rulquin \& Verité, 1993).

Na revisão feita por Santos et al. (1998), ficou claro que as fontes ricas em PNDR mais promissoras são farinha de peixe e farelo de soja tratado física ou quimicamente. Estes dados estão de acordo com Schwab (1994), visto que a farinha de peixe é a única fonte rica em PNDR que apresenta teor elevado tanto de lisina como de metionina, em proporções adequadas. O farelo de soja, apesar de deficiente em metionina é boa fonte de lisina e apresenta o melhor índice médio para os 10 aminoácidos essenciais (Chandler, 1989).

Em termos de balanceamento de dietas para vacas leiteiras, Schwab (1994), propôs inicialmente que a produção de proteína do leite seria maximizada quando os teores de lisina e de metionina fossem de $15 \%$ e $5 \%$, respectivamente, em relação ao total de aminoácidos essenciais do conteúdo duodenal. O grupo francês trabalhando com o sistema PDI, tem proposto comercialmente que o PDI deve conter $6,9 \%$ de lisina e 2,1 de metionina (Rulquin \& Verité, 1993).

Mais recentemente, com o desenvolvimento de modelos dinâmicos como o CNCPS (Russell et al., 1992), tem sido possível balancear o teor de lisina e metionina na proteína metabolizável no intestino delgado de vacas leiteiras. Sloan et al. (1999), ajustaram a recomendação do sistema PDI (Rulquin \& Verité, 1993) em termos de lisina e metionina para o sistema de proteina metabolizável do CNCPS, chegando à recomendação de $6,82 \%$ de lisina e $2,19 \%$ de metionina na proteína metabolizável.

A edição recente do NRC (2001) representa uma significativa evolução no tocante à nutrição protéica de vacas leiteiras. O modelo trabalha com adequação de proteína metabolizável e permite ajustes nos teores de aminoácidos, especialmente lisina e metionina na proteína metabolizável. 
Devido a este fato é de extrema importância a utilização de fontes de proteína que apresentem boa qualidade de PNDR, ou seja, que apresentem um perfil de aminoácidos adequado.

\subsubsection{Uso de soja na nutrição de ruminantes}

A soja é uma excelente fonte de proteína vegetal, mas também apresenta em sua composição hidratos de carbono, vitaminas, minerais e fibra.

A proteína da soja é considerada como sendo de alta qualidade em termos de aminoácidos essenciais. Utilizando a proteina do leite como referência para a determinação do escore de aminoácidos essenciais no sistema MPS (milk protein score), o farelo de soja foi classificado como a segunda melhor fonte protéica para a produção de leite, atrás apenas da proteína microbiana (Chandler; 1989), a qual apresenta o maior escore.

As proteínas da soja apresentam um bom balanceamento desses aminoácidos, quando comparadas às de outros vegetais. Entretanto, como é comum às leguminosas, as proteínas da soja apresentam um teor reduzido dos aminoácidos sulfurados, metionina e cistina, e um teor elevado do aminoácido lisina (Chandler, 1989; Schwab, 1994).

A soja contém cerca de $35 \%$ de carboidratos totais. Os carboidratos insolúveis são celulose e hemicelulose, contendo também uma fração lignina encontrados na casca do grão. A sacarose é o principal açúcar solúvel presente em seus grãos e representa cerca de $5 \%$ do total de carboidratos. Os outros açúcares são os oligossacarídeos estaquiose $(3,8 \%)$ e rafinose $(1,2 \%)$ que, devido a complexidade das suas moléculas, são de difícil digestão, causando sintomas de flatulência em monogástricos.

Comparando-se também a composição química da soja com a de outros alimentos, evidencia-se sua superioridade em relação a outros vegetais, e sua equivalência em relação aos produtos animais. Entretanto, apesar de relativamente ser de boa qualidade, a fração de PNDR é baixa comparada com 
fontes de proteína de origem animal. Para tanto, vários métodos físicos e químicos de tratamento da soja estão sendo aplicados para se aumentar os teores de PNDR. A tostagem do grão de soja a fim de aumentar os níveis de PNDR, tem propiciado alguns resultados positivos (Faldet \& Satter, 1991; Socha \& Satter, 1991; Tice et al., 1993) e pode vir a ser uma fonte protéica interessante em nosso meio devido à elevada disponibilidade de soja grão no Brasil.

Com o aquecimento no processo de tostagem, a reação de Maillard (responsável pela formação de um complexo de maior resistência à degradação ruminal) é facilitada. A qualidade final da ST é função da temperatura utilizada no processo e do tempo em que o grão recebeu calor. Ganesh \& Grieve (1990) ao avaliar 3 temperaturas de tostagem $\left(125,150\right.$ e $\left.165^{\circ} \mathrm{C}\right)$ com o tempo de 45 a 65 segundos, 43 a 63 segundos, e 50 a 70 segundos, respectivamente, observaram a diminuição na solubilidade do nitrogênio. Entretanto, a degradabilidade não foi afetada, a não ser em relação à SC que obteve maior degradabilidade comparada com a ST. Hsu \& Satter (1995), trabalhando com 12 tipos de tratamento (temperatura $x$ tempo) chegaram a conclusão que a exposição do grão de soja por 1,0 a 1,5 minutos a uma temperatura de $146{ }^{\circ} \mathrm{C}$, seguido de um descanso de 30 minutos em silos metálicos hermeticamente fechados, foi o tratamento que apresentou o melhor desempenho de vacas leiteiras.

Segundo Abdelgadir et al. (1984) e Reddy et al. (1994) o uso de grão de soja processado numa temperatura ótima suporta melhores performances em novilhos do que o próprio farelo de soja.

Quando o grão de soja é tostado de maneira correta, seu teor de PNDR pode ser elevado até $60 \%$ do total de proteína do cereal, diminuindo assim a concentração de $\mathrm{NH}_{3}$ ruminal e aumentando a produção de leite (Tice et al., 1993). Entretanto, o teor de PNDR também é influenciado pelo tamanho de partícula, variando de $60 \%$ da proteína total para o grão inteiro a até $29 \%$ para o grão moído. 
O uso de grão de soja é interessante em dietas de vacas em lactação uma vez que nesta oleaginosa, energia e proteina se encontram em niveis elevados. A energia do grão de soja é elevada devido ao seu alto teor de óleo na matéria seca (aproximadamente 20\%). Esta característica pode ser interessante quando se deseja aumentar a densidade energética da dieta. Contudo, processos de extrusão e tostagem são utilizados como métodos afim de se aumentar os níveis de PNDR e a destruição de fatores anti-nutricionais, como o inibidor de tripsina, urease e redução da atividade da lipase (Mielke, 1981 citado por Scott, 1991), tendo alta aceitação pelos animais.

O uso do grão de soja na dieta destes animais vem crescendo a cada dia não só no Brasil mas também em outras regiões produtoras deste cereal por ser uma fonte de proteína e gordura extremamente conveniente e econômica.

\subsection{Síntese de proteína microbiana no rúmen}

Contendo ao redor de $60 \%$ da matéria seca em proteina, as bactérias ruminais são fonte constante deste nutriente para o animal. No rúmen, as bactérias requerem fontes de nitrogênio, energia, minerais, vitaminas e outros fatores para que possam crescer. Entretanto, nitrogênio e energia são requeridos em quantidades maiores e exercem maior influência no crescimento microbiano (Hoover \& Stokes, 1991).

Quando a proteína é degradada mais rapidamente que a fonte de energia, ocorre um excesso de amônia, que passa para o sistema circulatório para ser convertida em uréia no fígado. Essa uréia pode voltar ao rúmen e ser reciclada, mas a maior proporção é excretada na urina. Norlan (1975) observou em seus estudos que mais de $25 \%$ da proteína dietética é perdida na forma de amônia ruminal.

A flora microbiana do rúmen é capaz de sintetizar proteína utilizandose de fontes de nitrogênio não protéico (NNP), como por exemplo a uréia, que 
possui baixo custo por unidade de N. Estudos conduzidos em laboratório ("in vitro") na década de 70 e 80 sugeriram que a síntese de PM era maximizada com niveis muito baixos de amônia ruminal (Satter \& Slyter, 1974). Entretanto, valores mais elevados têm sido proposto por outros autores (Santos et al., 1998).

Vacas produzindo em torno de $4.500 \mathrm{~kg}$ leite/ano foram capazes de atender suas exigências por proteína somente através da utilização de NNP (Virtanen, 1966). Porém, vacas especializadas com produções da ordem de 9.000 a $14.000 \mathrm{~kg}$ leite/ano são inaptas a atender seus requerimentos em aminoácidos apenas através da síntese microbiana e necessitam da inclusão de fontes protéicas com baixa degradabilidade ruminal (Sloan et al., 1999).

A fermentabilidade dos carboidratos possui uma larga influência na utilização de $\mathrm{N}$ pelo rúmen e no crescimento microbiano $e$ isso se torna importante para suprir as necessidades de vacas de alta produção (Theurer et al., 1995).

O requerimento bacteriano de nutrientes é uma função das exigências de mantença e de crescimento do microrganismo. Portanto, quanto maiores os custos para mantença, menor o crescimento microbiano, o que ocorre em parte devido ao desacoplamento energético, que pode ser influenciado pelo desbalanço de nutrientes e condições ambientais do rúmen (Russell et al., 1992).

A amônia é utilizada como fonte preferencial de nitrogênio para bactérias fermentadoras de fibra (Hungate, 1966; Russell et al., 1992). Aquelas que fermentam amido, açúcares e substratos secundários para a síntese protéica também requerem amônia, porém têm suas sínteses aumentadas quando possuem à disposição peptídeos e aminoácidos (Cotta \& Russell, 1982; Russell et al., 1992). Esta amônia pode ser proveniente de proteínas verdadeiras de alimentos através de deaminação microbiana ou pode vir diretamente de nitrogênio não protéico. 
Vários gêneros de bactérias ruminais são consideradas como amilolíticas, podendo-se citar como exemplos alguns deles, como Bacterioides, Butyrivibrio, Eubacterium, Lactobacillus, Ruminobacter, Selenomonas, Streptococcus, Succinomonas e Succinovibrio (Kotarski et al., 1992; Van Soest, 1994).

As enzimas atuantes das espécies amilolíticas agem clivando aleatoriamente as moléculas de amido (Yokoyama \& Johnson, 1988). Após serem geradas maltose, maltotrioses e glicose a partir do amido e dextranas (Bergman, 1990), as bactérias sacarolíticas encarregam-se de fermentar tais substratos, produzindo piruvato, intermediário na produção de AGV (Fahey \& Berger, 1988).

\subsubsection{Fatores que afetam a sintese microbiana}

Apesar do fluxo microbiano ser predito pela quantidade de MO fermentável no rúmen, a produção microbiana pode não estar paralela à quantidade de carboidrato fermentável quando fatores necessários ao crescimento estão ausentes, ou quando alguns fatores aumentam os custos de mantença (NRC, 2001).

O crescimento microbiano e o fluxo microbiano para o intestino delgado (ID) podem ser afetados por vários fatores, dentre eles, a ingestão de alimento, a relação forragem:concentrado, as fontes e quantidades de carboidratos não estruturais, de proteína e de gordura na dieta, a frequência alimentar, o processamento de forragens e grãos, os métodos de conservação de forragens, a suplementação de micronutrientes, os tamponantes alimentares, os sais e ionóforos, e as condições ambientais (Sniffen \& Robinson, 1987).

Além da ingestão de matéria seca (IMS) influenciar a quantidade e o tipo de substrato disponivel para síntese microbiana, ela também afeta vários parâmetros ruminais ( $\mathrm{pH}$, taxa de diluição), sendo que a ingestão de forragem 
pode favorecer a eficiência de síntese microbiana, provavelmente pela combinação de aumento de fluxo de saliva, aumento da renovação de líquido (aumenta a lavagem de bactérias acopladas à pequenas partículas), aumento de $\mathrm{pH}$ (melhorando o ambiente ruminal), redução dos custos totais de mantença (microrganismos velhos são lavados e uma população mais juvenil é formada) (NRC, 2001).

\subsection{Sincronismo entre energia e proteína no rúmen}

A técnica de sincronismo da degradação ruminal entre energia e proteína propõe incrementar a utilização destes nutrientes visando um aumento na produção microbiana no rúmen. Essa maximização da síntese microbiana é responsável por um maior fluxo de aminoácidos para o intestino e também uma melhor eficiência da fermentação ruminal (Hoover \& Stokes, 1991).

A maior disponibilidade ruminal de amido, aumentando o nível de energia para os microorganismos, leva a uma melhor utilização da amônia ruminal evitando perdas (Nocek \& Tamminga, 1991; Hoover \& Stokes, 1991). Estas perdas podem chegar a $89 \%$ do nitrogênio consumido, do qual $25 \%$ são da amônia ruminal não utilizada pelos microorganismos para síntese de proteína (Norlan, 1975).

Milton et al. (1997) verificaram que um aumento na PDR através da adição de uréia $(0,05 \%)$ proporcionou uma melhor digestão ruminal da matéria orgânica e do amido sem que comprometesse o fluxo de $\mathrm{N}$ total e $\mathrm{N}$-bacteriano para o intestino delgado.

Casper et al. (1990) através de sua revisão, concluíram que a síntese de PM no rúmen e a eficiência de utilização da PDR podem ser maximizadas variando a fonte de carboidrato não estrutural (CNE) e a degradabilidade destes em dietas de vaca em lactação, pois diversos trabalhos reportaram um aumento de utilização de amônia para a sintese de PM quando dietas continham grandes quantidades de amido degradável no rúmen (Theurer et al., 1999). 
A taxa de degradação da fonte energética é o principal fator limitante para a utilização de NNP, o que pode ser ilustrado pelo ensaio de Casper \& Schingoethe (1986), que obtiveram produções de leite semelhantes a dieta de FS quando uréia foi incluída em dietas contendo $30 \%$ de soro seco como fonte de CNE rapidamente fermentável na mistura concentrada. 


\section{MATERIAL E MÉTODOS}

\subsection{Animais e instalações experimentais}

Foram utilizadas quatro vacas holandesas, multíparas, canuladas no rúmen e duodeno, com produção média de leite de $23 \mathrm{~kg} /$ dia e 130 dias de lactação no início do período experimental, em um delineamento do tipo Quadrado Latino $4 \times 4$.

O experimento foi conduzido nas instalações do Departamento de Produção Animal da Escola Superior de Agricultura "Luiz de Queiroz" Universidade de São Paulo no período de Janeiro a Junho de 1999. Os animais foram alojados em um galpão coberto equipado com ventiladores e mantidos em baias individuais do tipo "tie stall" $(2,5 \mathrm{~m} \times 1,1 \mathrm{~m})$. As baias eram equipadas com comedouros individuais e bebedouros automáticos.

\subsection{Tratamentos}

As dietas continham $50 \%$ de silagem de milho, $27 \%$ de milho, $15 \%$ de grão de soja, $4,5 \%$ de farelo de soja, $2,8 \%$ de mistura mineral e $0,7 \%$ de cloreto de potássio e foram formuladas para conterem $13,6 \%$ de PB.

Os tratamentos consistiram na comparação entre combinações de fontes energéticas e protéicas com diferentes degradabilidades, através do uso de dois tipos de processamento do milho (milho moido grosso-MMG e milho floculado-MF $360 \mathrm{~g} / \mathrm{L}$ ) e processamento ou não do grão de soja (soja tostadaST e soja crua-SC). 
Foi utilizado um arranjo fatorial $2 \times 2$ com os seguintes tratamentos: MF $360 \mathrm{~g} / \mathrm{L}$ e SC (MF+SC); MF $360 \mathrm{~g} / \mathrm{L}$ e ST (MF+ST); MMG e SC (MMG+SC) e MMG e ST (MMG+ST) (Tabela 1). Os tratamentos com MF e SC caracterizavam-se por conterem amido e proteína de alta degradabilidade ruminal respectivamente, enquanto que aqueles que continham MMG e ST por apresentar níveis maiores de amido e proteína não degradáveis no rúmen.

Tabela 1. Proporção dos ingredientes e composição média nutricional das dietas experimentais.

\begin{tabular}{lccccc}
\hline & \multicolumn{5}{c}{ TRATAMENTOS } \\
\cline { 2 - 3 } \cline { 5 - 6 } \cline { 5 - 6 } Ingredientes & SC & ST & SC & ST \\
\hline Silagem de milho & 50 & 50 & 50 & 50 \\
Farelo de soja & 4,5 & 4,5 & 4,5 & 4,5 \\
MF & 27,03 & 27,03 & - & - \\
MMG & - & - & 27,03 & 27,03 \\
Soja grão crua & 15 & - & & 15 & - \\
ST & - & 15 & - & 15 \\
Minerais & 3,4 & 3,4 & 3,4 & 3,4 \\
Cloreto de Potássio & 0,07 & 0,07 & 0,07 & 0,07 \\
& & & & \\
Composição & & & & \\
MS & 39,55 & 42,13 & 40,30 & 43,12 \\
FDN & 28,37 & 28,25 & 27,56 & 29,25 \\
FDA & 16,89 & 17,10 & 17,73 & 16,79 \\
Cinzas & 6,65 & 7,33 & 7,03 & 7,42 \\
PB & 14,17 & 13,60 & 13,38 & 13,65 \\
EE & 4,05 & 3,97 & 4,15 & 3,77 \\
Amido & 28,99 & 29,62 & 30,79 & 31,55 \\
\hline
\end{tabular}

Em cada horário de fornecimento do alimento, cada ingrediente era pesado individualmente e posteriormente misturado no cocho do animal.

A dieta foi fornecida à vontade de forma a permitir sobras de $5 \%$ em cada turno de alimentação, que correspondiam à 12 horas de intervalo, ou seja, 
às 6:00 horas e às 18:00 de cada dia, simultaneamente ao horário de ordenha dos animais.

Ao começo de cada período de coleta eram feitas as médias de consumo de cada animal durante os 6 últimos dias do período de adaptação. Essa quantidade média era fornecida aos animais durante o periodo de coleta e as sobras colocadas diretamente no rúmen antes do fornecimento do próximo tratamento.

\subsection{Período experimental}

O experimento foi conduzido durante o verão de 1999. Cada período experimental era composto de 14 dias, sendo 10 dias para a adaptação ao tratamento e mais 4 dias de coleta. Durante o período de adaptação os animais foram soltos diariamente para exercício e banho de sol em um piquete próximo às instalações por 1 hora/dia. No período de coleta os animais permaneceram todo o tempo no galpão onde eram alimentados.

\subsection{Administração de Itérbio (marcador externo)}

Durante um período de 10 dias, a começar no quarto dia de adaptação e se estendendo até o último dia de coleta, os animais foram submetidos à dosagens de cloreto de itérbio hexahidratado (1 $\mathrm{mg} / \mathrm{dia})$. Primeiramente foi realizado uma diluição deste sal com uma solução de ácido clorídrico $1 \mathrm{~N}$ na proporção de 1:1 (peso/volume), segundo Prigge et al. (1981).

\subsection{Protocolo de coletas}

\subsubsection{Pesagem e amostragem do alimento oferecido e recusado}

Os alimentos foram amostrados separadamente durante os 4 dias de coleta de cada período e compostos por vaca e período. $\mathrm{O}$ alimento recusado, 
que era retirado somente antes do fornecimento da alimentação vespertina foi totalmente introduzido no rúmen do animal. As amostras do alimento oferecido foram congeladas a $-10{ }^{\circ} \mathrm{C}$ para posterior análise químico-bromatológica.

\subsubsection{Produção e composição de leite}

As vacas foram ordenhadas em sistema de balde ao pé duas vezes ao dia às 6:00 horas e às 18:00 horas em todo o período experimental. Nos 4 dias de coleta, após a ordenha de cada animal, o leite era pesado e então coletado uma alíquota para formar uma amostra composta das 2 ordenhas realizadas no dia. Terminado o período de coleta as amostras foram enviadas para o laboratório de análises de leite do Departamento de Produção Animal ESALQ-USP para análise de sua composição, utilizando o método de infravermelho.

\subsubsection{Coleta de bolo alimentar do duodeno}

Durante o período de coleta de cada sub-período, amostras do bolo alimentar do duodeno, equivalente a $500 \mathrm{~mL}$, foram coletadas em intervalos de 4 horas, adiantando-se uma hora por dia, de modo que cada hora do dia fosse amostrada, perfazendo um total de aproximadamente 12 litros para cada animal. O material coletado foi armazenado a $-10^{\circ} \mathrm{C}$ para posterior análise químico-bromatológica.

Uma segunda amostragem do bolo alimentar do duodeno, também equivalente à $500 \mathrm{~mL}$, foi realizada a cada 4 horas durante 24 horas do penúltimo dia do período de coleta somando um total de 3 litros. O material foi batido em liquidificador por 1 minuto, coado em panos de fralda, armazenado em refrigerador por no máximo 24 horas e centrifugado a baixa rotação $(2.000 \mathrm{x}$ $G$ por 15 minutos) recuperando-se o sobrenadante. O sobrenadante sofreu uma nova centrifugação a $18.000 \times \mathrm{G}$ durante 15 minutos, após a qual desprezou-se 
a parte líquida e o material sedimentado foi coletado para formação de um "pellet" rico em bactérias, congelado a $-10^{\circ} \mathrm{C}$ para posterior análise.

\subsubsection{Coleta de fezes}

Amostras de fezes de aproximadamente $200 \mathrm{~g}$ foram obtidas do reto dos animais duas vezes ao dia em horário fixo, ou seja, às 7 horas e às 19 horas de cada dia durante os 4 dias de coleta. Estas amostras foram agrupadas por vaca e período e armazenadas a $-10^{\circ} \mathrm{C}$.

\subsubsection{Coleta de dados para determinação dos parâmetros ruminais}

No primeiro dia de coleta de cada período, o fluído ruminal foi coletado em intervalo de 2 horas durante 24 horas. A amostragem foi realizada em 4 pontos diferentes do rúmen e posteriormente coado em panos de fralda. Os $300 \mathrm{~mL}$ de líquido ruminal de cada animal em determinado horário foi imediatamente submetido à leitura de pH em um potenciômetro digital Digimed (modelo TE-902). Após à leitura do $\mathrm{pH}$ foram separadas 2 alíquotas de $25 \mathrm{~mL}$ cada e congeladas à $-10^{\circ} \mathrm{C}$ sem o uso de conservante (Nocek et al., 1987), para posterior análise de amônia e AGV.

\subsubsection{Coleta de dados para determinação dos parâmetros sanguíneos}

A coleta de sangue durante cada sub-período foi realizada através da punção na veia coccígea em intervalos de 2 horas, nos tempos $0,2,4,6,12 \mathrm{e}$ 18 horas após o fornecimento matinal de alimento. Os sangue foi coletado em tubos a vácuo contendo antiglicolítico (fluoreto de sódio) e anticoagulante (oxalato de potássio). Logo após a coleta, as amostras foram centrifugadas a 3.000 x G por 15 minutos com posterior coleta do plasma em "eppendorff" e congeladas à $-10^{\circ} \mathrm{C}$ para análise da concentração de uréia e glicose. 


\subsection{Preparo das amostras e análises laboratoriais}

\subsubsection{Análises químico-bromatológicas}

As amostras do alimento oferecido, do bolo alimentar do duodeno e das fezes foram secas a $65^{\circ} \mathrm{C}$ durante 72 horas, moídas em moinho com peneira de $1 \mathrm{~mm}$ e analisadas para MS, MO, PB de acordo com a AOAC (1990), amido pelo método descrito por Poore et al. (1991), fibra em detergente neutro (FDN), fibra em detergente ácido (FDA) e lignina de acordo com método de Van Soest et al. (1991). As amostras do alimento oferecido também foram analisadas quanto ao teor de EE, de acordo com a AOAC (1990).

As amostras de bolo duodenal e fecal foram analisadas para itérbio e os "pellets" de bactérias foram analisados para purina, segundo Zinn \& Owens (1986).

\subsubsection{Análise de glicose e uréia plasmática}

As amostras de plasma sanguíneo foram submetidas à determinação de glicose diretamente em um auto-analisador YSI 2.700 Select (Biochemistry Analyser - Yellow Spring, $\mathrm{OH}$, EUA). Para a análise da uréia plasmática, usouse o método de Chaney \& Marbach (1962), adaptando o método para leitura em aparelho Microplate Reader (Bio Rad - absorbância de 550 nanômetros), com resultado expresso em $\mathrm{mg} / \mathrm{dL}$.

\subsubsection{Análise de amônia e AGV no fluido ruminal}

Amostras do fluido ruminal foram descongeladas e centrifugadas a $12.000 \times \mathrm{G}$ a $4^{\circ} \mathrm{C}$, durante 30 minutos, sendo retirado $40 \mu \mathrm{L}$ do sobrenadante para posterior análise de AGV, de acordo com Palmquist \& Conrad (1971), utilizando tubos HP 5890 para leitura em cromatógrafo líquido gasoso (CLG) equipado com integrador HP (Hewlett-Packard Company, Avondale, PA). Outra 
alíquota de $1 \mathrm{~mL}$ foi obtida do sobrenadante para análise da concentração de amônia, de acordo com Chaney \& Marbach (1962) adaptado para leitura em aparelho Microplate Reader (Bio Rad - absorbância de 550 nanômetros), com resultado expresso em $\mathrm{mg} / \mathrm{dL}$.

\subsection{Análise estatística}

O delineamento experimental foi o Quadrado Latino $4 \times 4$ com um arranjo fatorial $2 \times 2$.

Os resultados referentes ao consumo de alimento, produção e composição de leite e digestibilidade de nutrientes foram avaliados utilizando-se o PROC GLM do programa estatístico SAS (1990).

Para as análises dos dados referentes a parâmetros sangüíneos e ruminais, os quais foram medidos no tempo, foi utilizado o PROC MIXED do programa estatístico SAS (1990).

Os parâmetros ruminais $(\mathrm{pH}$, concentração de amônia, concentração molar total dos AGV, porcentagens molares de acetato, propionato, butirato, isobutirato, isovalerato, valerato e relação acetato:propionato) foram analisados dentro dos tempos de coleta $0,2,4,6,8,10,12,14,16,18,20$ e 22 horas e os parâmetros sangüineos (uréia e glicose plasmática), dentro dos tempos de coleta $0,2,4,6,12$ e 18 horas.

Tanto para os parâmetros ruminais como para os sangüíneos considerou-se o horário de fornecimento matinal de alimento como o tempo zero.

Os resumos dos quadros de análise de variância estão apresentados nas Tabelas 2, 3 e 4 . 
Tabela 2. Resumo esquemático da análise de variância para consumo de MS, eficiência alimentar, produção e composição do leite e digestibilidade dos nutrientes.

\begin{tabular}{cc}
\hline Causas de Variação & Graus de Liberdade \\
\hline Animal & 3 \\
Período & 3 \\
Tratamento & 3 \\
Resíduo & 6 \\
TOTAL & 15 \\
\hline
\end{tabular}

Tabela 3. Análise de variância para os parâmetros ruminais.

\begin{tabular}{cc}
\hline Causas de Variação & Graus de Liberdade \\
\hline Animal & 3 \\
Período & 3 \\
Tratamento & 3 \\
Resíduo A & 6 \\
Sub TOTAL & 15 \\
Tempo & 11 \\
Tempo x Tratamento & 33 \\
Resíduo B & 132 \\
TOTAL & 191 \\
\hline
\end{tabular}

Tabela 4. Análise de variância para os parâmetros sangüíneos.

\begin{tabular}{cc}
\hline Causas de Variação & Graus de Liberdade \\
\hline Animal & 3 \\
Período & 3 \\
Tratamento & 3 \\
Residuo A & 6 \\
Sub TOTAL & 15 \\
Tempo & 5 \\
Tempo x Tratamento & 15 \\
Resíduo B & 60 \\
TOTAL & 95 \\
\hline
\end{tabular}




\section{RESULTADOS}

\subsection{Consumo de matéria seca}

Os dados relativos ao consumo de MS estão apresentados na Tabela 5.

O consumo de matéria seca, em $\mathrm{kg} / \mathrm{dia}$, não foi afetado pelos tratamentos $(P>0,05)$.

\subsection{Produção e composição do leite}

Os resultados de produção e composição do leite estão ilustrados na Tabela 5.

Houve uma tendência $(P=0,122)$ de efeito de fonte energética em produção de leite com valores mais elevados para o grão floculado em comparação com o moído grosso, entretanto, a produção de leite corrigido para $3,5 \%$ de gordura (LCG) não foi afetada pelo processamento do milho.

A tostagem da soja não resultou $(P>0,05)$ em melhor desempenho lactacional das vacas, tendo as produções de leite e de LCG sido semelhantes para dietas com diferentes processamento de soja.

Houve tendência $(P=0,12)$ de redução nos teores de gordura do leite com a floculação do milho, entretanto, devido à maior produção de leite com $M F$, a produção de gordura não foi afetada $(P>0,05)$ pelo processamento mais intenso do grão de cereal.

A suplementação de uma fonte rica em PNDR não afetou $(P>0,05) 0$ teor nem a produção de gordura do leite. 
O teor e a produção de proteína do leite não foram afetadas $(P>0,05)$ pelo processamento tanto da fonte energética como da fonte protéica. Entretanto, houve uma tendência de interação $(P<0,09)$ entre fonte de energia e proteína para estes dois parâmetros. Em presença de MF, valores mais elevados de teor e produção de proteína foram observados com a suplementação de soja crua, enquanto que em presença de MMG, a suplementação com ST resultou em valores mais elevados.

Os teores e as produções tanto de lactose quanto de sólidos totais não foram afetadas pelos tratamentos $(P>0,05)$.

Tabela 5. Valores médios de consumo de MS, produção e composição do leite.

\begin{tabular}{|c|c|c|c|c|c|c|c|}
\hline \multirow[b]{2}{*}{ Parâmetros } & \multicolumn{2}{|c|}{ MF } & \multicolumn{2}{|c|}{$\mathrm{MMG}$} & \multicolumn{3}{|c|}{$\mathrm{Pr}=\mathrm{F}$} \\
\hline & $\mathrm{SC}$ & ST & $\mathrm{SC}$ & ST & FE & FP & $\mathrm{FE}^{*} \mathrm{FP}$ \\
\hline Consumo, $\mathrm{kg} / \mathrm{d}$ & 18,50 & 18,50 & 18,50 & 24,50 & 0,1066 & 0,1066 & 0,1066 \\
\hline Produção, kg/d & 23,82 & 22,88 & 21,89 & 22,49 & 0,1222 & 0,8054 & 0,2759 \\
\hline $\mathrm{LCG}^{1}, \mathrm{~kg} / \mathrm{d}$ & 23,25 & 21,63 & 21,97 & 22,94 & 0,9836 & 0,7634 & 0,2587 \\
\hline $\begin{array}{r}\text { Proteína, } \% \\
, \mathrm{~kg} / \mathrm{d}\end{array}$ & $\begin{array}{l}3,32 \\
0,79\end{array}$ & $\begin{array}{l}3,03 \\
0,68\end{array}$ & $\begin{array}{l}2,93 \\
0,64\end{array}$ & $\begin{array}{l}3,36 \\
0,74\end{array}$ & $\begin{array}{l}0,8744 \\
0,3962\end{array}$ & $\begin{array}{l}0,7161 \\
0,9857\end{array}$ & $\begin{array}{l}0,0890 \\
0,0768\end{array}$ \\
\hline $\begin{array}{r}\text { Gordura, } \% \\
, \mathrm{~kg} / \mathrm{d}\end{array}$ & $\begin{array}{l}3,35 \\
0,79\end{array}$ & $\begin{array}{l}3,17 \\
0,72\end{array}$ & $\begin{array}{l}3,53 \\
0,77\end{array}$ & $\begin{array}{l}3,65 \\
0,81\end{array}$ & $\begin{array}{l}0,1205 \\
0,5556\end{array}$ & $\begin{array}{l}0,9003 \\
0,7729\end{array}$ & $\begin{array}{l}0,4372 \\
0,2991\end{array}$ \\
\hline $\begin{array}{r}\text { Lactose, } \% \\
, \mathrm{~kg} / \mathrm{d}\end{array}$ & $\begin{array}{l}4,97 \\
1,18\end{array}$ & $\begin{array}{l}4,88 \\
1,12\end{array}$ & $\begin{array}{l}4,93 \\
1,08\end{array}$ & $\begin{array}{l}4,90 \\
1,10\end{array}$ & $\begin{array}{l}0,8413 \\
0,2493\end{array}$ & $\begin{array}{l}0,3360 \\
0,6957\end{array}$ & $\begin{array}{l}0,5908 \\
0,3850\end{array}$ \\
\hline $\begin{array}{r}\mathrm{ST}^{2}, \% \\
, \mathrm{~kg} / \mathrm{d}\end{array}$ & $\begin{array}{c}12,51 \\
2,98\end{array}$ & $\begin{array}{c}11,91 \\
2,71\end{array}$ & $\begin{array}{c}12,20 \\
2,67\end{array}$ & $\begin{array}{c}12,77 \\
2,85\end{array}$ & $\begin{array}{l}0,5625 \\
0,5988\end{array}$ & $\begin{array}{l}0,9773 \\
0,7929\end{array}$ & $\begin{array}{l}0,2335 \\
0,1798\end{array}$ \\
\hline $\operatorname{CCS}^{3}(\times 1000)$ & 248,75 & 70,94 & 180,69 & 110,38 & 0,8155 & 0,0790 & 0,3952 \\
\hline
\end{tabular}

1 LCG: leite corrigido para 3,5\% de gordura

2 ST: sólidos totais

3 CCS: contagem de células somáticas 


\subsection{Parâmetros ruminais}

\subsubsection{Concentração de nitrogênio amoniacal no rúmen}

Os dados resultantes da análise de concentração de $\mathrm{N}$-amoniacal no rúmen constam na tabela 6 .

Tabela 6. Valores de quadrados mínimos da concentração de amônia ruminal $(\mathrm{mg} / \mathrm{dL})$.

\begin{tabular}{cccccc}
\hline \multirow{2}{*}{ TEMPO $^{1}$} & \multicolumn{2}{c}{ MF } & \multicolumn{2}{c}{ MMG } & \multirow{2}{*}{ Sub-parcelas $^{2}$} \\
\cline { 2 - 5 } Dieta 06:00 hrs & $\mathrm{SC}$ & $\mathrm{ST}$ & $\mathrm{SC}$ & $\mathrm{ST}$ & \\
0 & 6,55 & 6,11 & 6,77 & 6,53 & $6,49 \mathrm{e}$ \\
2 & $16,20 \mathrm{a}$ & $9,04 \mathrm{~d}$ & $14,52 \mathrm{~b}$ & $11,69 \mathrm{c}$ & $12,87 \mathrm{~b}$ \\
4 & $15,80 \mathrm{~b}$ & $13,44 \mathrm{~d}$ & $17,61 \mathrm{a}$ & $13,96 \mathrm{c}$ & $15,21 \mathrm{a}$ \\
6 & $10,12 \mathrm{a}$ & $8,44 \mathrm{c}$ & $9,49 \mathrm{~b}$ & $10,23 \mathrm{a}$ & $9,57 \mathrm{c}$ \\
Dieta 18:00 hrs & & & & & \\
12 & 6,63 & 5,57 & 6,36 & 5,13 & $5,92 \mathrm{f}$ \\
18 & 9,01 & 8,43 & 8,95 & 7,71 & $8,52 \mathrm{~d}$ \\
Parcela $^{3}$ & $10,72 \mathrm{~A}$ & $8,50 \mathrm{~B}$ & $10,62 \mathrm{~A}$ & $9,21 \mathrm{~B}$ & \\
\hline
\end{tabular}

1 Tempo, em horas, após o fornecimento matinal de alimento

2 Média das sub-parcelas (tempos)

3 Média das parcelas (tratamentos)

abc Médias na mesma coluna seguidas de letras distintas diferem entre si a $5 \%$ de significância

AB Médias na mesma linha seguidas de letras distintas diferem entre si a $5 \%$ de significância

Erro padrão da média (EPM) para tempos $=0,2614 ; \mathrm{EPM}$ dos tratamentos $=0,2530$

Valores de probalidade do teste $F$ : $F E=0,013 ; F P=0,0001 ; F E^{\star} F P=0,0033$; tempo $=0,0001$; $F E^{\star} F P^{\star}$ tempo $=0,0001$ 


\subsection{2 $\mathrm{pH}$ ruminal}

Os dados resultantes da leitura de $\mathrm{pH}$ ruminal estão apresentados na Tabela 7.

Os valores médios diários de $\mathrm{pH}$ (parcelas) não foram afetados pelos tratamentos $(P>0,05)$.

$\mathrm{O}$ pH variou $(\mathrm{P}<0,05)$ entre os valores médios de cada tempo de coleta (sub-parcelas) e teve seus maiores valores médios no momento anterior ao fornecimento do alimento da manhã e da tarde $(6,43$ e 6,55, respectivamente). Os menores valores de $\mathrm{pH}$ ocorreram 6 horas após o fornecimento do alimento da manhã $(0,44$ unidades menor) e da tarde $(0,57$ unidades menor) .

Tabela 7. Valores de quadrados minimos do $\mathrm{pH}$ ruminal.

\begin{tabular}{cccccc}
\hline \multirow{2}{*}{ TEMPO $^{1}$} & \multicolumn{2}{c}{ MF } & \multicolumn{2}{c}{ MMG } & \multirow{2}{*}{ Sub-parcelas } \\
\cline { 2 - 5 } & SC & ST & SC & ST & \\
\hline Dieta 6:00 hrs & $6,41 \mathrm{a}$ & $6,54 \mathrm{a}$ & $6,45 \mathrm{a}$ & $6,34 \mathrm{a}$ & $6,43 \mathrm{a}$ \\
0 & $6,16 \mathrm{a}$ & $6,25 \mathrm{a}$ & $6,19 \mathrm{a}$ & $6,06 \mathrm{a}$ & $6,17 \mathrm{bc}$ \\
2 & $6,09 \mathrm{a}$ & $6,05 \mathrm{a}$ & $6,16 \mathrm{a}$ & $5,95 \mathrm{a}$ & $6,07 \mathrm{~cd}$ \\
4 & $5,77 \mathrm{~b}$ & $6,14 \mathrm{a}$ & $5,99 \mathrm{ab}$ & $6,08 \mathrm{ab}$ & $5,99 \mathrm{~d}$ \\
6 & $6,11 \mathrm{a}$ & $6,08 \mathrm{a}$ & $5,99 \mathrm{a}$ & $6,03 \mathrm{a}$ & $6,05 \mathrm{~cd}$ \\
8 & $6,20 \mathrm{a}$ & $6,42 \mathrm{a}$ & $6,29 \mathrm{a}$ & $6,29 \mathrm{a}$ & $6,30 \mathrm{~b}$ \\
10 & & & & & \\
Dieta 18:00 hrs & $6,42 \mathrm{a}$ & $6,66 \mathrm{a}$ & $6,57 \mathrm{a}$ & $6,56 \mathrm{a}$ & $6,55 \mathrm{a}$ \\
12 & $6,04 \mathrm{a}$ & $6,23 \mathrm{a}$ & $6,11 \mathrm{a}$ & $6,00 \mathrm{a}$ & $6,09 \mathrm{~cd}$ \\
14 & $5,90 \mathrm{a}$ & $6,15 \mathrm{a}$ & $6,19 \mathrm{a}$ & $5,92 \mathrm{a}$ & $6,04 \mathrm{~cd}$ \\
16 & $5,90 \mathrm{a}$ & $5,99 \mathrm{a}$ & $6,10 \mathrm{a}$ & $5,94 \mathrm{a}$ & $5,98 \mathrm{~d}$ \\
18 & $6,07 \mathrm{a}$ & $6,08 \mathrm{a}$ & $6,22 \mathrm{a}$ & $6,22 \mathrm{a}$ & $6,15 \mathrm{c}$ \\
20 & $6,22 \mathrm{a}$ & $6,13 \mathrm{a}$ & $6,26 \mathrm{a}$ & $6,24 \mathrm{a}$ & $6,21 \mathrm{cc}$ \\
22 & 6,11 & 6,23 & 6,21 & 6,14 & \\
\hline Parcela $^{3}$ & & & &
\end{tabular}

1 Tempo, em horas, após o fornecimento matinal de alimento

2 Média das sub-parcelas (tempos)

3 Média das parcelas (tratamentos)

abc Médias na mesma coluna seguidas de letras distintas diferem entre si a $5 \%$ de significância

Erro padrăo da média $(E P M)$ para tempos $=0,5126$; $E P M$ dos tratamentos $=0,0292$

Valores de probalidade do teste $F: F E=0,9600 ; F P=0,8081$; $F E{ }^{\star} F P=0,2875$; tempo $=0,0001$; $F E^{\star} F P^{*}$ tempo $=0,7118$ 


\subsection{3 Ácidos graxos voláteis}

\subsubsection{1 Ácidos graxos voláteis totais}

Os dados resultantes da análise de AGV totais estão apresentados na Tabela 8.

Houve tendência $(P=0,107)$ de uma maior produção de AGV para os animais recebendo MF em comparação com o MMG.

As maiores concentrações de AGV foram observadas ao redor de 6 horas após o primeiro fornecimento de alimento.

Tabela 8. Valores de quadrados mínimos da concentração total de AGV no rúmen $(\mathrm{mM})$.

\begin{tabular}{|c|c|c|c|c|c|}
\hline \multirow{2}{*}{ TEMPO $^{1}$} & \multicolumn{2}{|c|}{ MF } & \multicolumn{2}{|c|}{ MMG } & \multirow{2}{*}{ sub-parcelas } \\
\hline & $\mathrm{SC}$ & ST & $\mathrm{SC}$ & ST & \\
\hline \multicolumn{6}{|l|}{ Dieta 6:00 hrs } \\
\hline 0 & 135,35 & 125,74 & 150,73 & 129,18 & $130,61 \mathrm{bc}$ \\
\hline 2 & 124,90 & 120,10 & 122,89 & 119,54 & $121,86 \mathrm{c}$ \\
\hline 4 & 149,40 & 136,27 & 129,97 & 134,07 & $137,43 \mathrm{~b}$ \\
\hline 6 & 133,71 & 155,86 & 152,40 & 160,42 & $150,60 \mathrm{a}$ \\
\hline 8 & 145,02 & 140,94 & 127,71 & 137,39 & $137,76 \mathrm{ab}$ \\
\hline 10 & 122,05 & 147,94 & 138,15 & 139,58 & $136,93 \mathrm{bc}$ \\
\hline \multicolumn{6}{|l|}{ Dieta 18:00 hrs } \\
\hline 12 & 127,48 & 140,66 & 145,78 & 143,77 & $139,42 \mathrm{ab}$ \\
\hline 14 & $121,45 \mathrm{a}$ & $88,88 \mathrm{~b}$ & $100,26 \mathrm{ab}$ & $95,47 \mathrm{ab}$ & $101,52 \mathrm{~d}$ \\
\hline 16 & $111,44 \mathrm{a}$ & $91,86 \mathrm{~b}$ & $77,18 \mathrm{~b}$ & $128,08 \mathrm{a}$ & $102,14 \mathrm{~d}$ \\
\hline 18 & 116,22 & 106,85 & 109,05 & 126,62 & $114,68 \mathrm{~cd}$ \\
\hline 20 & $172,43 \mathrm{a}$ & $161,71 \mathrm{a}$ & $101,47 b$ & $103,61 \mathrm{~b}$ & $134,80 \mathrm{bc}$ \\
\hline 22 & $152,68 \mathrm{a}$ & $150,73 \mathrm{a}$ & $99,37 \mathrm{~b}$ & $115,33 b$ & $129,53 \mathrm{bc}$ \\
\hline Parcela ${ }^{3}$ & 134,34 & 130,63 & 119,70 & 127,76 & \\
\hline
\end{tabular}

1 Tempo, em horas, após o fornecimento matinal de alimento

2 Média das sub-parcelas (tempos)

3 Média das parcelas (tratamentos)

abc Médias na mesma coluna seguidas de letras distintas diferem entre si a $5 \%$ de significância

Erro padrão da média (EPM) para tempos $=12,48 ;$ EPM dos tratamentos $=12,00$

Valores de probalidade do teste $F$ : $F E=0,1017 ; F P=0,6494 ; F E{ }^{\star} F P=0,2421$; tempo $=0,0001$; $F E^{\star} F P^{\star}$ tempo $=0,0009$ 


\subsubsection{2 Ácido acético}

Os dados resultantes da análise da porcentagem molar de acetato estão apresentados na Tabela 9.

A concentração molar de acetato no líquido ruminal foi maior $(P<0,05)$ nas dietas contendo MF em comparação com moído grosso. Os valores mais elevados de acetato foram observados ao redor de 6 horas após o fornecimento de alimento.

A substituição do SC por ST resultou em porcentagens molares de acetato no líquido ruminal similares $(P>0,05)$.

Tabela 9. Valores de quadrados mínimos da concentração $(\mathrm{mM})$ de acetato no rúmen.

\begin{tabular}{|c|c|c|c|c|c|}
\hline \multirow{2}{*}{ TEMPO $^{1}$} & \multicolumn{2}{|c|}{ MF } & \multicolumn{2}{|c|}{$\mathrm{MMG}$} & \multirow{2}{*}{ Sub-parcelas ${ }^{2}$} \\
\hline & $\mathrm{SC}$ & $\mathrm{ST}$ & $\mathrm{SC}$ & ST & \\
\hline \multicolumn{6}{|l|}{ Dieta 6:00 hrs } \\
\hline 0 & 87,45 & 83,09 & 88,64 & 85,49 & $86,17 \quad b$ \\
\hline 2 & 81,61 & 81,49 & 81,65 & 80,30 & $81,26 \mathrm{~b}$ \\
\hline 4 & 100,57 & 92,09 & 89,03 & 83,07 & $91,19 \mathrm{ab}$ \\
\hline 6 & 85,59 & 104,65 & 100,52 & 105,61 & 99,09 a \\
\hline 8 & 92,68 & 95,02 & 82,04 & 88,80 & $89,63 \mathrm{ab}$ \\
\hline 10 & 77,70 & 96,49 & 91,50 & 89,04 & $88,68 \mathrm{ab}$ \\
\hline \multicolumn{6}{|l|}{ Dieta $18: 00 \mathrm{hrs}$} \\
\hline 12 & 79,55 & 91,58 & 96,51 & 96,45 & $91,02 \mathrm{ab}$ \\
\hline 14 & 73,44 & 53,88 & 64,34 & 59,54 & $62,80 \mathrm{c}$ \\
\hline 16 & $65,28 \mathrm{ab}$ & $57,77 \mathrm{~b}$ & $34,44 c$ & $81,85 a$ & 59,83 c \\
\hline 18 & $70,98 \mathrm{a}$ & $54,27 \mathrm{~b}$ & $64,66 \mathrm{ab}$ & $83,01 \mathrm{a}$ & $68,23 c$ \\
\hline 20 & $118,45 a$ & $107,50 \mathrm{a}$ & $44,54 \mathrm{~b}$ & $55,26 \mathrm{~b}$ & $81,44 \mathrm{~b}$ \\
\hline 22 & $104,24 a$ & $102,75 \mathrm{a}$ & $52,44 b$ & $70,24 b$ & 82,42 b \\
\hline Parcela $^{3}$ & 86,46 & 85,05 & 74,19 & 81,55 & \\
\hline
\end{tabular}

1 Tempo, em horas, após o fornecimento matinal de alimento

2 Média das sub-parcelas (tempos)

3 Média das parcelas (tratamentos)

abc Médias na mesma coluna seguidas de letras distintas diferem entre si a $5 \%$ de significância

Erro padrão da média $(E P M)$ para tempos $=8,29 ; E P M$ dos tratamentos $=7,87$

Valores de probalidade do teste $F$ : $F E=0,0445 ; F P=0,3761 ; F E * F P=0,2081$; tempo $=0,0001$; FE* FP $^{*}$ tempo $=0,0001$ 


\subsubsection{3 Ácido propiônico}

Os dados resultantes da análise da concentração de propionato em relação ao total de AGV estão apresentados na Tabela 10.

Tabela 10. Valores de quadrados mínimos da concentração (mM) de propionato no rúmen.

\begin{tabular}{|c|c|c|c|c|c|}
\hline \multirow{2}{*}{ TEMPO $^{1}$} & \multicolumn{2}{|c|}{$\mathrm{MF}$} & \multicolumn{2}{|c|}{$\mathrm{MMG}$} & \multirow{2}{*}{ Sub-parcelas ${ }^{2}$} \\
\hline & $\mathrm{SC}$ & ST & $\mathrm{SC}$ & $\mathrm{ST}$ & \\
\hline \multicolumn{6}{|l|}{ Dieta 6:00 hrs } \\
\hline 0 & 29,84 & 25,82 & 27,67 & 27,32 & $27,66 \mathrm{c}$ \\
\hline 2 & 26,30 & 23,28 & 26,37 & 24,45 & $25,10 \mathrm{c}$ \\
\hline 4 & 29,45 & 26,73 & 26,00 & 32,07 & 28,56 bc \\
\hline 6 & 27,40 & 31,28 & 31,72 & 34,11 & $31,13 b$ \\
\hline 8 & 30,82 & 27,65 & 28,47 & 29,42 & $29,09 \mathrm{bc}$ \\
\hline 10 & 25,82 & 30,42 & 29,93 & 31,29 & $29,37 \mathrm{bc}$ \\
\hline \multicolumn{6}{|l|}{ Dieta 18:00 hrs } \\
\hline 12 & 29,69 & 29,35 & 32,61 & 30,30 & $30,49 \mathrm{bc}$ \\
\hline 14 & 29,79 & 22,54 & 25,15 & 23,15 & $25,15 \mathrm{c}$ \\
\hline 16 & 28,17 & 23,59 & 31,36 & 30,60 & 28,43 bc \\
\hline 18 & 28,52 & 32,80 & 27,47 & 26,99 & $28,95 \mathrm{bc}$ \\
\hline 20 & 35,94 & 36,86 & 38,21 & 36,58 & $36,90 \mathrm{a}$ \\
\hline 22 & 31,28 & 32,44 & 30,00 & 33,60 & $31,83 \mathrm{~b}$ \\
\hline Parcela $^{3}$ & 29,42 & 28,56 & 29,58 & 29,99 & \\
\hline
\end{tabular}

1 Tempo, em horas, após o fornecimento matinal de alimento

2 Média das sub-parcelas (tempos)

3 Média das parcelas (tratamentos)

abc Médias na mesma coluna seguidas de letras distintas diferem entre si a $5 \%$ de significância

Erro padrão da média (EPM) para tempos $=3,31$; $E P M$ dos tratamentos $=3,25$

Valores de probalidade do teste $F$ : $F E=0,4855 ; F P=0,8419 ; F E^{\star} F P=0,5751$; tempo $=0,0001$; $F E^{\star} F P^{\star}$ tempo $=0,1816$

Os tratamentos (parcelas) não afetaram $(P>0,05)$ a porcentagem molar de propionato no rúmen.

As maiores concentrações de propionato ruminal foram observadas 6 horas após o fornecimento das dietas pela manhã. 


\subsubsection{4 Ácido butírico}

Os dados resultantes da análise da concentração de butirato em relação ao total de AGV estão apresentados na Tabela 11. butirato $(P>0,05)$.

Não houve efeito de tratamento na concentração diária média de

Os valores mais elevados de butirato, foram observados 6 horas após a primeira alimentação.

Tabela 11. Valores de quadrados mínimos da concentração $(\mathrm{mM})$ de butirato no rúmen.

\begin{tabular}{|c|c|c|c|c|c|}
\hline \multirow{2}{*}{ TEMPO $^{1}$} & \multicolumn{2}{|c|}{ MF } & \multicolumn{2}{|c|}{$\mathrm{MMG}$} & \multirow{2}{*}{ Sub-parcelas ${ }^{2}$} \\
\hline & $\mathrm{SC}$ & ST & $\mathrm{SC}$ & ST & \\
\hline \multicolumn{6}{|l|}{ Dieta 6:00 hrs } \\
\hline 0 & 13,15 & 12,26 & 11,52 & 11,96 & $12,22 \mathrm{bc}$ \\
\hline 2 & 12,11 & 11,04 & 10,60 & 10,50 & $11,06 \mathrm{c}$ \\
\hline 4 & $14,30 \mathrm{a}$ & $11,88 \mathrm{ab}$ & $10,70 \mathrm{~b}$ & $13,44 \mathrm{ab}$ & $12,58 \mathrm{~b}$ \\
\hline 6 & 13,95 & 14,12 & 13,94 & 15,15 & $14,29 \mathrm{a}$ \\
\hline 8 & 15,25 & 12,29 & 12,26 & 13,71 & $13,38 \mathrm{ab}$ \\
\hline 10 & 13,22 & 14,80 & 12,14 & 13,85 & $13,50 \mathrm{ab}$ \\
\hline \multicolumn{6}{|c|}{ Dieta $18: 00 \mathrm{hrs}$} \\
\hline 12 & 12,47 & 14,25 & 12,01 & 12,19 & $12,73 \mathrm{ab}$ \\
\hline 14 & $12,21 \mathrm{ab}$ & $12,25 \mathrm{a}$ & $7,34 b$ & $9,10 \mathrm{~b}$ & $10,23 \mathrm{c}$ \\
\hline 16 & 12,83 & 9,68 & 13,81 & 10,98 & $11,83 \mathrm{bc}$ \\
\hline 18 & 11,36 & 13,96 & 13,06 & 11,64 & $12,50 \mathrm{bc}$ \\
\hline 20 & 12,85 & 12,00 & 14,29 & 12,86 & $13,00 \mathrm{ab}$ \\
\hline 22 & 12,05 & 10,57 & 12,69 & 12,30 & $11,90 \mathrm{bc}$ \\
\hline Parcela ${ }^{3}$ & 12,98 & 12,43 & 12,03 & 12,31 & \\
\hline
\end{tabular}

1 Tempo, em horas, após o fornecimento matinal de alimento

2 Média das sub-parcelas (tempos)

3 Média das parcelas (tratamentos)

abc Médias na mesma coluna seguidas de letras distintas diferem entre si a $5 \%$ de significância

Erro padrão da média $(E P M)$ para tempos $=1,37$; $E P M$ dos tratamentos $=1,33$

Valores de probalidade do teste $F$ : $F E=0,3658 ; F P=0,8100 ; F E * F P=0,4753$; tempo $=0,0005$; $F E^{\star} F P^{\star}$ tempo $=0,0943$ 


\subsubsection{Relação acetato:propionato}

Os dados referentes à análise da relação acetato/propionato estão apresentados na Tabela 12.

Houve efeito de tratamento na relação acetato/propionato $(P<0,05)$, com maiores relações nas dietas contendo MF.

Houve efeito $(P<0,05)$ do tempo de coleta (sub-parcelas) sobre a relação acetato:propionato no fluído ruminal, com os valores mais elevados ocorrendo nos tempos 2 e 4 horas. No momento do fornecimento da dieta, observou-se relações de 3,16 e 3,01 nas coletas realizadas de manhã e de tarde, respectivamente.

Tabela 12. Valores de quadrados mínimos da relação acetato:propionato produzidos no rúmen.

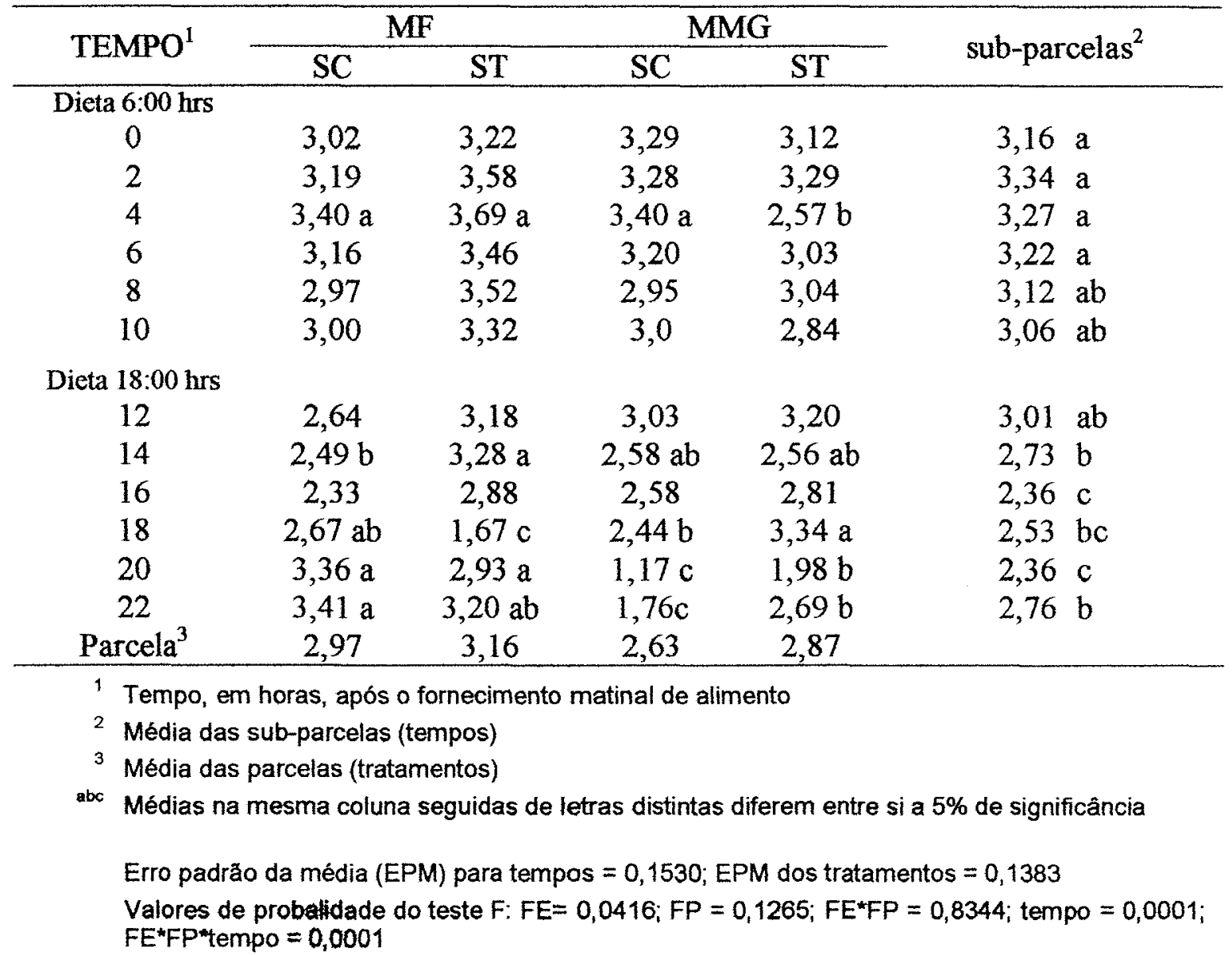




\subsubsection{6 Ácido isobutírico e valérico}

Os dados referentes à análise da concentração molar de isobutirato e valerato estão apresentados na Tabela 13.

Houve efeito $(P<0,05)$ de floculação do milho e de tostagem da soja na concentração ruminal de isobutirato. Valores mais elevados foram observados para MF comparado com MMG e para soja cru comparada com ST.

Houve interação significativa $(P<0,05)$ entre fonte energética e fonte protéica, uma vez que a maior diferença na concentração de isobutirato entre aos fontes protéicas, ocorreu em presença de MF.

Tabela 13. Valores de quadrados mínimos da concentração de isobutirato e valerato no rúmen.

\begin{tabular}{cccccc}
\hline \multirow{2}{*}{ AGV } & \multicolumn{2}{c}{ MF } & \multicolumn{2}{c}{ MMG } & \multirow{2}{*}{ EPM } \\
\cline { 2 - 5 } & SC & ST & SC & ST & \\
\hline Valerato & 1,78 & 1,65 & 1,55 & 1,66 & 0,1734 \\
Isobutirato & $1,33 \mathrm{a}$ & $0,90 \mathrm{~b}$ & $0,96 \mathrm{~b}$ & $0,88 \mathrm{~b}$ & 0,0790 \\
\hline
\end{tabular}

abc Médias na mesma coluna seguidas de letras distintas diferem entre si a $5 \%$ de significância

Erro padrão da média (EPM) para tempos $=0,1776$ (valerato)

EPM para tempos $=0,0784$ (isobutirato)

Valores de probalidade do teste $F: F E=0,2118 ; F P=0,9172 ; F E * F=0,1787$; tempo $=0,0001$; $\mathrm{FE}^{\star} \mathrm{FP}^{\star}$ tempo $=0,8918$ (valerato)

Valores de probalidade do teste $F$ : $F E=0,0297 ; F P=0,0086 ; F E{ }^{\star} F P=0,0386$; tempo $=0,0001$;

FE*F*tempo $=0,0058$ (isobutirato) 


\subsection{Parâmetros sanguíneos}

\subsubsection{Glicose plasmática}

Os dados resultantes da análise de glicose plasmática estão exibidos na Tabela 14.

Tabela 14. Valores médios da concentração de glicose plasmática (mg/dL).

\begin{tabular}{cccccc}
\hline \multirow{2}{*}{ TEMPO $^{1}$} & \multicolumn{2}{c}{ MF } & \multicolumn{2}{c}{ MMG } & \multirow{2}{*}{ Sub-parcelas $^{2}$} \\
\cline { 2 - 4 } & SC & ST & SC & ST & \\
\hline Dieta 6:00 hrs & & & & & \\
0 & 51,52 & 52,97 & 48,11 & 53,72 & $51,58 \mathrm{a}$ \\
2 & 51,55 & 46,57 & 47,37 & 51,10 & $49,15 \mathrm{ab}$ \\
4 & 46,87 & 48,95 & 46,82 & 48,15 & $47,70 \mathrm{~b}$ \\
6 & 51,97 & 47,80 & 46,82 & 51,62 & $49,55 \mathrm{ab}$ \\
Dieta 18:00 hrs & & & & & \\
12 & 47,70 & 50,55 & 50,40 & 50,65 & $49,82 \mathrm{ab}$ \\
18 & 51,75 & 52,95 & 47,77 & 49,47 & $50,48 \mathrm{ab}$ \\
Parcela $^{3}$ & 50,23 & 49,96 & 47,88 & 50,78 & \\
\hline
\end{tabular}

1 Tempo, em horas, após o fornecimento matinal de alimento

2 Média das sub-parcelas (tempos)

3 Média das parcelas (tratamentos)

abc Médias na mesma coluna seguidas de letras distintas diferem entre si a $5 \%$ de significância

Erro padrão da média $(E P M)$ para tempos $=2,91 ;$ EPM dos tratamentos $=2,92$

Valores de probalidade do teste $F$ : $F E=0,5263 ; F P=0,2879 ; F E{ }^{*} F P=0,2117$; tempo $=0,2082$; FE*FP*tempo $=0,6635$

Houve efeito $(P<0,05)$ do tempo de coleta (sub-parcelas) sobre a concentração plasmática de glicose, com os valores mais altos ocorrendo nos tempos 0 e 18 horas. No momento do fornecimento da dieta, observou-se valores médios de 51,58 e 49,82 mg/dL nas coletas realizadas de manhã e de tarde, respectivamente.

Não se observou diferença $(P>0,05)$ na concentração de glicose entre os valores médios diários de cada tratamento (parcelas) nem na interação tratamento $\times$ tempo. 


\subsubsection{Uréia plasmática}

Os dados resultantes da análise de uréia plasmática estão apresentados na Tabela 15.

Houve efeito $(P<0,05)$ na concentração plasmática de uréia entre os tempos de coleta (sub-parcelas) mas não entre os tratamentos. No momento do fornecimento da dieta, observou-se valores médios de 12,14 e 10,64 mg/dL nas coletas realizadas de manhã e de tarde, respectivamente.

Tabela 15. Valores médios da concentração de uréia plasmática (mg N/dL).

\begin{tabular}{cccccc}
\hline \multirow{2}{*}{ TEMPO $^{1}$} & \multicolumn{2}{c}{ MF } & \multicolumn{2}{c}{ MMG } & \multirow{2}{*}{ sub-parcelas $^{2}$} \\
\cline { 2 - 4 } Dieta $6: 00$ hrs & SC & ST & SC & ST & \\
0 & 10,83 & 12,67 & 12,22 & 12,83 & $12,14 \mathrm{a}$ \\
2 & 12,20 & 10,58 & 13,10 & 11,52 & $11,85 \mathrm{ab}$ \\
4 & 11,89 & 11,61 & 11,41 & 11,39 & $11,57 \mathrm{ab}$ \\
6 & 10,07 & 11,94 & 10,26 & 12,33 & $11,15 \mathrm{ab}$ \\
Dieta $18: 00$ hrs & & & & & $10,64 \mathrm{~b}$ \\
12 & 10,38 & 11,48 & 10,16 & 10,55 & $11,68 \mathrm{ab}$ \\
18 & 10,96 & 12,73 & 10,49 & 12,57 & \\
\hline Parcela $^{3}$ & 11,05 & 11,83 & 11,27 & 11,86 & \\
\hline
\end{tabular}

1 Tempo, em horas, após o fornecimento matinal de alimento

2 Média das sub-parcelas (tempos)

3 Média das parcelas (tratamentos)

abc Médias na mesma coluna seguidas de letras distintas diferem entre si a $5 \%$ de significância

Erro padrão da média (EPM) para tempos $=0,4890 ; E P M$ dos tratamentos $=0,5086$

Valores de probalidade do teste $F$ : $F E=0,8156 ; F P=0,2266 ; F E^{\star} F P=0,8595$; tempo $=0,3302$; FE*FP*tempo $=0,5033$ 


\subsection{Digestibilidade de nutrientes}

Os dados resultantes da análise da digestibilidade ruminal e no trato total estão apresentados na Tabela 16.

A digestibilidade ruminal e no trato total da matéria seca não apresentaram diferença entre os tratamentos $(P>0,05)$.

A digestibilidade aparente da proteína no trato total apresentou tendência $(P=0,1250)$ de ser maior nos tratamentos que continham ST $(80,48 \%)$ em relação aos tratamentos com SC $(77,07 \%)$.

A digestibilidade ruminal e total do amido não foram afetadas pelo processamento do milho $(P>0,05)$. Houve tendência de efeito negativo da tostagem do grão de soja $(P=0,0614)$ na digestibilidade ruminal do amido. Os tratamentos com SC apresentaram digestibilidades ruminais do amido, em torno de $75,10 \%$ e os com ST de $70,88 \%$.

Houve diferença $(P<0,05)$ para a digestibilidade do FDA no rúmen influenciado pela interação entre fontes de proteína e energia com valor superior para o tratamento MMG+ST $(70,77 \%)$.

Tabela 16. Digestibilidade dos nutrientes (\%MS).

\begin{tabular}{|c|c|c|c|c|c|c|c|c|}
\hline \multirow{2}{*}{ Digestibilidade $\%$} & \multicolumn{2}{|c|}{ MF } & \multicolumn{2}{|c|}{ MMG } & \multirow{2}{*}{ EPM } & \multicolumn{3}{|c|}{$\operatorname{Pr}=F$} \\
\hline & $\mathrm{SC}$ & ST & $\mathrm{SC}$ & ST & & $\mathrm{FE}$ & FP & FP*FP \\
\hline \multicolumn{9}{|l|}{ Ruminal } \\
\hline MS & 48,85 & 41,10 & 45,29 & 48,69 & 0,0450 & 0,6705 & 0,6465 & 0,2619 \\
\hline PB & 34,87 & 37,12 & 37,01 & 35,00 & 0,0610 & 0,9983 & 0,9854 & 0,7396 \\
\hline Amido & 75,95 & 69,83 & 74,25 & 71,93 & 0,0184 & 0,9165 & 0,0614 & 0,3401 \\
\hline FDN & 57,53 & 45,51 & 52,91 & 53,88 & 0,0434 & 0,6805 & 0,2514 & 0,1852 \\
\hline FDA & 66,43 & 53,30 & 63,45 & 70,77 & 0,0395 & 0,1164 & 0,4895 & 0,0415 \\
\hline \multicolumn{9}{|l|}{ Trato Total } \\
\hline MS & 68,00 & 64,69 & 64,19 & 70,60 & 0,0320 & 0,7542 & 0,6467 & 0,1803 \\
\hline PB & 77,32 & 79,48 & 76,82 & 81,47 & 0,0190 & 0,7085 & 0,1250 & 0,5382 \\
\hline Amido & 93,77 & 92,81 & 93,16 & 93,94 & 0,0054 & 0,6630 & 0,8733 & 0,1643 \\
\hline FDN & 76,34 & 71,62 & 74,01 & 79,53 & 0,0348 & 0,4544 & 0,9125 & 0,1923 \\
\hline FDA & 70,49 & 69,06 & 75,30 & 76,99 & 0,0468 & 0,2231 & 0,9784 & 0,7505 \\
\hline
\end{tabular}




\subsection{Fluxo duodenal de nutrientes}

Não houve efeito significativo $(P>0,05)$ de tratamentos no fluxo duodenal da matéria seca, FDN e FDA.

A floculação do milho tendeu $(P=0,0915)$ a reduzir o fluxo duodenal do amido em comparação com a moagem grosseira, enquanto que a tostagem da soja aumentou $(P<0,05)$ o fluxo de amido para o intestino

Houve tendência $(P=0,1075)$ da floculação afetar o fluxo duodenal de proteína, havendo tendência $(P=0,0628)$ de interação entre fonte de energia e de proteína.

O fluxo duodenal de aminoácidos essenciais não foi afetado pelos tratamentos $(P>0,05)$.

Tabela 17. Fluxo de nutrientes para o duodeno $(\mathrm{g} / \mathrm{d})$.

\begin{tabular}{|c|c|c|c|c|c|c|c|}
\hline & \multicolumn{2}{|c|}{ MF } & \multicolumn{2}{|c|}{ MMG } & \multicolumn{3}{|c|}{$\operatorname{Pr}=F$} \\
\hline & $\mathrm{SC}$ & ST & $\mathrm{SC}$ & ST & $\mathrm{FE}$ & FP & $\mathrm{FE}^{*} \mathrm{FP}$ \\
\hline \multicolumn{8}{|l|}{ Amido } \\
\hline Consumo, $\mathrm{kg} / \mathrm{d}$ & 5,89 & 5,39 & 5,74 & 7,14 & 0,1768 & 0,4200 & 0,1172 \\
\hline Fluxo, $\mathrm{kg} / \mathrm{d}$ & 1,40 & 1,57 & 1,47 & 1,96 & 0,0915 & 0,0259 & 0,2025 \\
\hline \multicolumn{8}{|l|}{ PB } \\
\hline Consumo, g/d & 2934 & 2956 & 2946 & 3918 & 0,1020 & 0,0968 & 0,1090 \\
\hline Fluxo, g/d & 1910 & 1775 & 1845 & 2479 & 0,1075 & 0,1895 & 0,0628 \\
\hline \multicolumn{8}{|l|}{$\mathrm{AAE}^{1}, \mathrm{~g} / \mathrm{d}$} \\
\hline MET & 27,72 & 29,65 & 25,07 & 34,80 & 0,9080 & 0,9401 & 0,6600 \\
\hline LIS & 195,02 & 181,37 & 168,60 & 185,15 & 0,6724 & 0,9564 & 0,5751 \\
\hline ARG & 184,65 & 175,94 & 163,70 & 189,20 & 0,8894 & 0,7624 & 0,5428 \\
\hline LEU & 295,28 & 296,21 & 270,28 & 327,90 & 0,9195 & 0,3913 & 0,4056 \\
\hline ILE & 157,68 & 147,35 & 141,09 & 165,39 & 0,9703 & 0,7218 & 0,3903 \\
\hline VAL & 184,09 & 165,76 & 158,14 & 183,08 & 0,8470 & 0,8823 & 0,3511 \\
\hline HIS & 75,41 & 69,21 & 67,25 & 80,70 & 0,8504 & 0,6836 & 0,2900 \\
\hline PHE & 163,12 & 149,76 & 146,11 & 177,46 & 0,7717 & 0,6278 & 0,2514 \\
\hline TRE & 161,67 & 145,04 & 145,24 & 152,74 & 0,8319 & 0,8245 & 0,5626 \\
\hline
\end{tabular}

1 AAE - aminoácidos essenciais; MET - metionina; LIS - lisina; ARG - arginina; LEU - leucina; ILE - isoleucina; VAL - valina; HIS - histidina; PHE - fenilalanina; TRE - treonina 


\section{DISCUSSÃO}

Assim como em outros trabalhos (Petit et al., 1997; Dhiman et al., 1997; Bernard et al., 1990; Bernard et al., 1995; Faldet \& Satter., 1991; Scott et al.,1991) a ingestão diária de matéria seca não foi diferente $(P>0,05)$ entre as dietas que continham SC e ST como fonte protéica. Mabjeesh et al. (1997) e Herrera-Saldana \& Huber(1989), estudando combinações entre fontes protéicas e de carboidratos com diferentes degradabilidades ruminais, também não observaram diferenças no consumo de matéria seca entre os tratamentos, estando de acordo com os dados obtidos neste estudo. O valor numérico mais elevado de consumo na dieta contendo ST e MMG é difícil de ser explicado.

A ausência de efeito $(P>0,05)$ da tostagem da soja nas produções de leite e de LCG, como visto na tabela 5, concordam com os dados de Petit et al. (1997), que também não verificaram diferença na produção de leite quando compararam grãos de leguminosas crus com extrusados em dietas à base de silagem de capim. De acordo com Voss et al. (1988), o tratamento térmico de grãos de leguminosas tem pouco ou nenhum efeito na produção de leite quando a dieta é a base de silagem de milho e que para se obter um incremento na produção de leite com fontes protéicas mais resistentes à degradação ruminal, o programa de alimentação deve basear-se em silagem de alfafa (Faldet \& Satter, 1991).

Faldet \& Satter (1991) verificaram diferença de $4 \mathrm{~kg} / \mathrm{d}$ de leite corrigido para $3,5 \%$ de gordura a mais para os tratamentos que continham ST em comparação com SC em uma dieta a base de silagem de alfafa. Estes dados foram confirmados em um estudo posterior (Dhiman et al., 1997), onde 
obteve-se um incremento de $2,3 \mathrm{~kg} / \mathrm{d}$ de leite corrigido para $3,5 \%$ de gordura para a ST quando comparada com a SC, em uma dieta com $33 \%$ de silagem de alfafa e $17 \%$ de silagem de milho. Solomon et al. (2000) também obtiveram aumentos de 7,8 a $10,5 \%$ com a adição de soja extrusada. Mabjeesh et al. (2000) verificando o aumento do nível de PNDR através do caroço de algodão sem línter tostado chegaram à mesma conclusão.

Santos et al. (1998) mostraram que, das fontes suplementares ricas em PNDR, a proteína da soja e da farinha de peixe são as que mais apresentam chances de aumentar a produção de leite de vacas de alta produção. Entretanto, as respostas são mais consistentes e mais expressivas em dietas contendo principalmente silagem de alfafa como volumoso, devido ao baixo teor de PNDR deste alimento.

A tendência $(P=0,12)$ de maior produção de leite nas dietas com MF obtida neste estudo encontra forte respaldo na literatura. Em recente revisão sobre o assunto, Theurer et al. (1999) compararam fontes de amido com diferentes degradabilidades ruminais e observaram aumento na produção de leite quando fontes mais degradáveis foram utilizadas. Yang et al. (2000) também observaram aumento na produção de leite quando se aumentou a degradabilidade ruminal do amido na dieta.

Ao combinar fontes protéicas e de amido com diferentes degradabilidades ruminais, Herrera-Saldana \& Huber (1989) encontraram maior produção para o tratamento que continha fonte de amido e de proteína com maior degradabilidade ruminal, apesar desta diferença não ter se estendida quando se corrigiu o leite para $3,5 \%$ de gordura. Neste mesmo trabalho a combinação que menos foi efetiva na produção de leite corrigido para $3,5 \%$ de gordura continha fonte de amido de alta degradabilidade e fonte de proteina com baixa degradabilidade.

Santos et al. (1999), apesar de não detectar diferença significativa, observaram que quando o tratamento continha MF e proteina de baixa 
degradabilidade ruminal a produção de leite foi $2,7 \mathrm{~kg} / \mathrm{dia}$ maior em comparação com os outros tratamentos que tinham combinações de diferentes degradabilidades ruminais entre fontes de energia e de proteína. No entanto, estes dados são suportados pela concepção que a proteína de baixa degradabilidade ruminal usada no estudo tinha alta qualidade e que o MF maximizou a produção e o fluxo de proteína microbiana para o intestino.

No presente experimento, o teor e a produção de proteína do leite não foram afetados $(P>0,05)$ pelo processamento tanto da fonte energética quanto da fonte protéica.

A literatura tem mostrado de forma consistente um maior teor e produção de proteína do leite quando se aumenta a degradabilidade ruminal das fontes de carboidratos não estruturais (Theurer et al., 1999).

Yu et al. (1997) observaram maior teor de proteína do leite em vacas alimentadas com MF em comparação com MMG. Menezes Jr. (1999) também observou maior teor e produção de proteína do leite do leite de vacas recebendo MF em comparação com MMG. Yang et al. (2000) explicam este fato justificando uma maior produção de propionato para a síntese de glicose, que poderia ter poupado 0 metabolismo de proteína para este fim $e$, consequentemente, aumentado a concentração deste nutriente no leite. No entanto, Lykos \& Varga (1995) atribuem o aumento da concentração de proteína no leite pelo fato de ter havido uma maior produção de massa microbiana no rúmen proporcionando um aumento em toda energia e proteína para o animal. Grummer et al. (1994) atribuem o fato a uma maior quantidade de aminoácidos chegando ao intestino delgado e pelo aumento na disponibilidade de energia para a glândula mamária devido a economia na detoxificação de $\mathrm{NH}_{3}$.

Segundo Santos (1998), o aumento no teor e produção de proteína do leite com fontes de amido de alta degradabilidade ruminal se devem a uma combinação de maior disponibilidade de energia, maior liberação de insulina 
(consequente da maior produção de propionato ruminal) e a um maior fluxo de proteína microbiana para o duodeno.

Verificando o efeito da extrusão em grãos de leguminosas, Petit et al. (1997) observaram uma maior porcentagem de proteína do leite ao se aumentar o nível de PNDR da dieta. O mesmo ocorreu quando se avaliou o efeito da tostagem do caroço de algodão (Pires et al.,1997). Mabjeesh et al. (2000) ao avaliar caroço de algodão tostado, obtiveram resultados superiores quando se avaliou a produção de proteína do leite, o que não ocorreu com sua concentração. Benchaar et al. (1994) e Pires et al. (1997) afirmam em seus estudos que o tratamento térmico com o objetivo de aumentar a concentração de PNDR aumenta o fluxo e a disponibilidade de aminoácidos para o duodeno, aumentando assim a utilização do mesmo para a secreção de proteína no leite.

Contrariamente, Bernard et al. (1995) e Tice et al. (1993) não observaram diferença entre a ST e a crua quanto ao teor de proteína do leite e Scott et al. (1991) observaram redução da concentração de proteína no leite quando a ST e a extrusada foram comparadas com o grão cru.

Santos et al. (1999) observaram aumento tanto na concentração quanto na produção de proteína do leite, quando combinaram MF e proteína de baixa degradabilidade ruminal e atribuíram este fato à maximização da produção de proteína microbiana e também pelo adequado perfil de aminoácidos da fonte de proteína de baixa degradabilidade ruminal.

Santos et al. (1998) relataram em extensa revisão de literatura que, em 21 comparações entre farelo de soja convencional e farelo tratado física ou quimicamente para elevar o teor de PNDR, o teor de proteína do leite foi afetado negativamente em 8 e não afetado nas 12 demais comparações. Em nenhuma comparação houve aumento no teor de proteína com a inclusão de PNDR.

A tendência observada no presente estudo de redução no teor de gordura do leite $(P=0,12)$ sem no entanto afetar negativamente a sua produção 
está de acordo com os dados revisados por Theurer et al. (1999), quando a degradabilidade do amido é aumentada via processamento.

Menezes Jr. (1999) também observou menor teor de gordura no leite de vacas recebendo dietas semelhantes às usadas no presente estudo, quando o MF foi comparado com o moído grosso.

Herrera-Saldana \& Huber (1989), avaliando a sincronização de degradabilidade entre proteína e amido, encontraram diferença para a porcentagem de gordura no leite quando a fonte de amido era o sorgo em comparação com a cevada, o que não ocorreu com a produção diária de gordura.

A maior concentração de gordura no leite observada quando a fonte de energia é de menor degradabilidade pode ser explicada pelo melhor ambiente ruminal em termos de $\mathrm{pH}$, minimizando o fluxo de ácidos graxos insaturados "trans" para a glândula mamaria (Theurer et al., 1999). Entretanto, no presente estudo o $\mathrm{pH}$ ruminal não foi diferente $(P>0,05)$ entre os tratamentos (Tabela 7).

A ausência de efeito $(P>0,05)$ de fonte protéica quanto a concentração de gordura do leite também foi observada por outros autores que avaliaram o tratamento térmico do grão de soja (Santos et al., 1999; Dhiman et al., 1997; Bernard et al., 1995; Faldet \& Satter, 1991; Tice et al., 1993). No entanto, Mabjeesh et al. (2000) verificaram aumento tanto na porcentagem quanto na produção de gordura quando caroço de algodão tostado foi incluido na dieta.

Outros parâmetros avaliados, como porcentagem e produção de lactose e sólidos totais do leite, não foram afetados pelos tratamentos $(P>0,05)$. Santos et al. (1999) obtiveram um aumento na lactose e sólidos totais do leite com o uso de MF e proteína de baixa degradabilidade ruminal. Os autores constataram que tanto a lactose quanto o teor de sólidos totais aumentaram 
quando a relação entre amido degradável no rúmen e proteína degradável aumentou.

Os dados resultantes da análise de concentração de $\mathrm{N}$-amoniacal no rúmen indicam que tanto o aumento da degradabilidade ruminal do amido quanto a redução da degradabilidade ruminal de proteína via floculação e tostagem, respectivamente, são mecanismos eficientes para reduzir perda de amônia no rúmen. Yang et al. (2000) observaram drástico declínio na concentração de amônia no fluído ruminal quando se aumentou o grau de processamento da fonte de amido, enquanto Shabi et al. (1998) constataram alta concentração de amônia ruminal quando a fonte de proteína era de alta degradabilidade e a fonte de amido era de baixa degradabilidade.

Como pode-se verificar na Tabela 7 , os tratamentos não afetaram $(P>0,05) \circ \mathrm{pH}$ ruminal. Menezes Jr. (1999) também não observou efeito da floculação no $\mathrm{pH}$ ruminal. Houve efeito do tempo de amostragem no $\mathrm{pH}$, sendo que os valores mais baixos foram observados entre 4 a 6 horas após 0 fornecimento das dietas.

A diferença entre as degradabilidades das fontes de amido em vários experimentos realizados tem se mostrado responsável pela diferença de $\mathrm{pH}$ ruminal. Quanto maior a intensidade de processamento do grão de cereal mais baixo é o pH devido a maior produção de AGV (Yang et al., 2000). Arieli et al. (1996) concluíram que a concentração de AGV no líquido ruminal sofre maior influência da degradabilidade ruminal da matéria orgânica do que da proteína. No presente experimento, houve tendência $(P=0,10)$ da floculação aumentar a concentração ruminal de AGV.

Igualmente ao estudo de Scott et al. (1991), no presente experimento não se observou diferença entre as concentrações totais de AGV entre os tratamentos com SC e ST. Mabjeesh et al. (2000), ao avaliarem o efeito do tratamento térmico sobre o caroço de algodão, também constataram que não houve diferença na concentração total de AGV. 
Shabi et al. (1998), trabalhando com combinações entre fontes de diferentes degradabilidades ruminais de amido e proteína encontraram diferença estatística na concentração ruminal de AGV para as dietas com alto teor de amido degradável no rúmen + alto teor de proteína degradável no rúmen e baixo teor de amido degradável no rúmen + baixo teor de proteína degradável no rúmen.

A concentração molar de acetato apresentou diferença significativa $(P<0,05)$ quando se variou a fonte de amido, ficando com os maiores valores os tratamentos que continham MF. Entretanto quando se substituiu SC pela tostada no presente experimento, não se observou diferenças entre as concentrações molares de acetato nem de propionato discordando dos valores encontrados por Scott et al. (1991), que verificaram maiores valores para os tratamentos com ST. Segundo estes autores, também foi observado a diminuição nos valores de propionato e aumento nos valores de butirato com o uso da ST, o que não ocorreu no presente experimento.

Houve efeito significativo $(P<0,05)$ dos tratamentos na relação acetato:propionato ruminal (Tabela 12). Esta relação acetato:propionato foi de 3,16 e 2,63 para baixa e alta degradabilidade ruminal da proteína concordando com Shabi et al. (1998) em seu trabalho sobre sincronização de energia e proteína no rúmen.

A não observância de efeito dos tratamentos sobre a concentração de glicose plasmática pode estar ligado provavelmente a não existência de diferença na concentração molar de propionato no líquido ruminal que, segundo Huntington (1997), é o principal substrato para a síntese de glicose (gluconeogênese) no fígado em vacas leiteiras.

Os dados resultantes da análise de uréia plasmática não apresentaram efeito $(P>0,05)$ significativo entre as dietas, mostrando que a diferença na concentração de amônia ruminal não foi suficiente para causar 
efeito tanto da fonte de proteína quanto da fonte de amido na concentração de uréia no plasma.

Abdelgadir et al. (1996) afirmam que a concentração de uréia no plasma sanguíneo não é influenciado apenas pela fonte de proteina, mas também pela sua concentração na dieta, que pode resultar em um alto catabolismo de aminoácidos para compensar um déficit na energia ou glicose ou no balanço inadequado de aminoácidos que chega ao intestino delgado.

Segundo Shabi et al. (1998), um decréscimo na concentração de uréia plasmática quando a concentração de $\mathrm{N}$-amoniacal no rúmen aumenta indica um melhor valor biológico da proteína microbiana que chega ao intestino do animal por conter mais protozoários. No entanto, esta diferença também pode estar ligada a uma melhor eficiência na utilização de amônia pelos microrganismos ou devido a um aumento na reciclagem desta através da passagem do sangue para o rúmen.

A digestibilidade da maioria dos nutrientes no rúmen e no trato digestivo total, não foi afetada pelos tratamentos $(P>0,05)$. Alguns trabalhos têm mostrado aumento na digestibilidade da matéria seca da dieta quando o milho ou o sorgo são floculados em comparação com a laminação ou moagem grosseira (Theurer et al., 1999). Esperava-se uma diferença significativa na digestibilidade do amido no rúmen e no trato digestivo total entre as formas de processamento do grão de milho, conforme relatado de forma consistente na literatura por Theurer et al. (1999).

Os valores para digestibilidade ruminal do amido do grão floculado de 69,83 a $75,95 \%$ estão abaixo dos encontrados na literatura (Theurer et al., 1999), entretanto, valores entre $72-74 \%$ para o MMG podem ser considerados altos (Huntington, 1997).

Os valores de $93 \%$ para digestibilidade do amido do MF no trato total estão de acordo com dados obtidos em estudos prévios em nosso laboratório (Menezes Jr., 1999), porém estes valores são inferiores aos relatados em 
trabalhos realizados nos Estados Unidos, enquanto que os valores observados para MMG podem ser considerados acima do esperado (Theurer et al., 1999; Huntington, 1997).

Trabalhando nas mesmas condições com MF e moído grosso, em dietas muito parecidas, Menezes Jr. (1999) obteve valores de digestibilidade do amido no trato total em torno de $93 \%$ para MF, contra $72 \%$ do MMG.

O maior fluxo de amido $(P<0,05)$ para 0 duodeno com a suplementação de ST, provavelmente ocorreu em função do elevado consumo observado na dieta MMG+ST, fato este sem uma explicação plausível.

O fluxo duodenal de $A A E$ não foi afetado pelos tratamentos. Trabalhos avaliando o fluxo de AAE para o duodeno em dietas contendo MF em comparação com milho moído ou apenas laminado são escassos na literatura (Santos, 1998). Tem sido sugerido que o uso de fontes de amido de alta degradabilidade ruminal poderia favorecer um maior fluxo de AAE para o intestino, principalmente de lisina e de metionina, em função de uma maior síntese de proteína microbiana no rúmen (NRC, 2001). No presente trabalho, a digestibilidade ruminal do amido não foi afetada pela floculação, o que justificaria os resultados observados de fluxo de AAE.

A tostagem da soja tem mostrado resultados inconsistentes quanto ao seu efeito no fluxo de AAE para o intestino, com efeito positivo em alguns estudos e ausência de efeito em outros (Santos et al., 1998).

Vale ressaltar que os valores baixos observados para o fluxo de metionina, sugerem problemas com a análise efetuada, com possibilidade de perda deste AAE durante a hidrólise ácida das amostras. 


\section{CONCLUSÕES}

A tentativa de melhorar 0 desempenho animal através da sincronização da degradação ruminal de energia e proteína não se mostrou vantajosa.

A utilização de fontes de amido de alta degradabilidade ruminal, como o MF, permite uma maior produção de leite em dietas contendo silagem de milho como volumoso exclusivo.

Não houve vantagem em aumentar o teor de PNDR das dietas através da tostagem do grão de soja para vacas produzindo em torno de 21 a $24 \mathrm{~kg}$ de leite/d. 


\section{REFERÊNCIAS BIBLIOGRÁFICAS}

ABDELGADIR, I.E.; MORRILL, J.L.; HIGGINS, J.J. Effect of roasted soybeans and corn on performance and ruminal and blood metabolites of dairy calves. Journal of Dairy Science, v.79, n.3, p.465-474, 1996.

ABDELGADIR, I.E.O.; MORRILL, J.L.; STUTTS, J.A.; MORRILL, M.B.; JOHNSON, D.E.; BEHNKE, K.C. Effect of processing temperature on utilization of whole soybeans by calves. Journal of Dairy Science, v.67, n.11, p.2554-2559, 1984.

ARIELI, A.; SHABI, Z.; BRUCKENTAL, I.; TAGARI, H.; AHARONI, Y.; ZAMWELL, S.; VOET, $H$. Effect of degradation of organic matter and crude protein on ruminal fermentation in dairy cows. Journal of Dairy Science, v.79, n.10, p.1774-1780, 1996.

ASSOCIATION OF OFFICIAL ANALYTICAL CHEMISTS. Official Methods of Analysis of the Association of Official Analytical Chemists. 15. ed., Arlington: The Association, 1990. 2v.

BEAUACHEMIN, K.A.; MCALLISTER T.A.; DONG, Y.; FARR B.I.; CHENG, K.J. Effects of mastication on digestion of whole cereal-grains by cattle. Journal of Animal Science, v.72, n.1, p.236-246, 1994.

BENCHAAR, C.; VERNAY, M.; BAYOURTHE, C.; MONCOULON, R. Effects of extrusion of whole horse beans on protein digestion and amino-acid-absorption in dairy-cows. Journal of Dairy Science, v.77, n.5, p.1360-1371, 1994.

BERGMAN, E.N. Energy contributions of volatile fatty-acids from the gastrointestinaltract in various species. Physiological Reviews, v.70, n.2, p. 567-590, 1990.

BERNARD, J.K.; KELLY, F.M. Influence of cottonseed meal or meat bone meal additions to diets containing wheat middlings fed to lactating Holstein cows. Journal of Dairy Science, v.73, suppl.1, p.170, 1990. 
BERNARD, J.K.; QUIGLEY, J.D.; DOWLEN, H.H.; LAMAR, K.C. Supplemental niacin and heat-treated whole soybeans for Jersey cows during early lactation. Journal of Dairy Science, v.78, n.9, p.2016-2023, 1995.

CASPER, D.P.; SCHINGOETHE, D.J. Evaluation of urea and dried whey in diets of cows during early lactation. Journal of Dairy Science, v.69, n.5, p.1346-1354, 1986.

CASPER, D.P.; SCHINGOETHE, D.J.; EISENBEISZ, W.A. Response of early lactation dairy cows fed diets varying in source of nonstructural carboydrate and crude protein. Journal of Dairy Science, v.73, n.4, p. 1039-1050, 1990.

CHANDLER, P.T. Achievement of optimum amino acid balance possible. Feedstuffs, v.61, n.26, p.14, 25, 1989.

CHANEY, A.L.; MARBACH, E.P. Modified reagents for determination of urea and ammonia. Clinical Chemistry, v.8, p.130-137, 1962.

COTTA, M.A.; RUSSEL, J.B. The effect of peptides and amino acids on efficiency of rumen bacterial protein synthesis in continuous culture. Journal of Dairy Science, v.65, p.226, 1982.

DELFINO, F.J. Identification and characterization of cereal grain tissues resistant to rumen microbial digestion using in situ, in vitro and scanning electron microscope techniques. Tucson, 1986. 1v. Thesis (Ph.D.) - University of Arizona.

DHIMAN, T.R.; KOREVAAR, A.C.; SATTER, L.D. Particle size of roasted soybeans and the effect on milk production of dairy cows. Journal of Dairy Science, v. $80, n .8$, p.1722-1727, 1997.

FAHEY Jr., G.C.; BERGER, L.L. Carbohydrate nutrition of ruminants. In: CHURCH, D.C. (Ed.) The ruminant animal: digestive physiology and nutrition. Englewood Cliffs: Prentice-Hall, 1988. cap.14, p.269-297.

FALDET, M.A.; SATTER, L.D. Feeding heat-treated full fat soybeans to cows in early lactation. Journal of Dairy Science, v.74, n.9, p.3047-3054, 1991.

GANESH, D.; GRIEVE, D.G. Effect of roasting raw soybeans at 3 temperatures on insitu dry-matter and nitrogen disappearance in dairy-cows. Journal of Dairy Science, v.73, n.11, p.3222-3230, 1990. 
GRUMMER, R.R.; LUCK, M.L.; BARMORE, J.A. Lactational performance of dairy cows fed raw soybeans, with or without animal by-product proteins, or roasted soybeans. Journal of Dairy Science, v.77, n.5, p. 1354-1359, 1994.

HERRERA-SALDANA, R.; HUBER, J.T. Influence of varying protein and starch degradabilities on performance of lactating cows. Journal of Dairy Science, v.72, n.6, p.1477-1483, 1989.

HOOVER, W.H.; STOKES, S.R. Balancing carbohydrates and proteins for optimum rumen microbial yield. Journal of Dairy Science, v.74, n.10, p.3630-3644, 1991.

HSU, J.T.; SATTER, L.D. Procedures for measuring the quality of heat-treated soybeans. Journal of Dairy Science, v.78, n.6, p.1353-1361, 1995.

HUNGATE, R.E. The rumen and its microbes. New York: Academic Press, 1966. $533 p$.

HUNTINGTON, G.B. Starch utilization by ruminants: from basics to the bunk. Journal of Animal Science, v.75, n.3, p.852-867, 1997.

KOTARSKI, S.F.; WANISKA, R.D.; THURN, K.K. Starch hydrolysis by the ruminal microflora. Journal of Nutrition, v.122, n.1, p.178-190, 1992.

LYKOS, T.; VARGA, G.A. Effects of processing method on degradation characteristics of protein and carbohydrate sources in situ. Journal of Dairy Science, v.78, n.8, p.1789-1801, 1995.

MABJEESH, S.J.; GALINDEZ, J.; KROLL, O.; ARIELI, A. The effect of roasting nonlinted whole cottonseedon milk production by dairy cows. Journal of Dairy Science, v.83, n.11, p.2557-2563, 2000.

MABJEESH, S.J.; ARIELI, A.; BRUCKENTAL, I.; ZAMWELL, S.; TAGARI, H. Effect of ruminal degradability of crude protein and nonstructural carbohydrates on the efficiency of bacterial crude protein synthesis and amino acid flow to the abomasum of dairy cows. Journal of Dairy Science, v.80, n.11, p.2939-2949, 1997.

MCALLISTER, T.A.; BAE, H.D.; JONES, G.A.; CHENG, K.J. Microbial attachment and feed digestion in the rumen. Journal of Animal Science, v.72, n.11, p.3004-3018, 1994. 
MENEZES Jr., M.P. Efeito do processamento do grão de milho e sua substituição parcial por polpa De citros peletizada sobre o desempenho, digestibilidade de nutrientes e parâmetros sanguineos de vacas de leite. Piracicaba, 1999. 97p. Dissertação (Mestrado) - Escola Superior de Agricultura "Luiz de Queiroz", Universidade de São Paulo.

MIELKE C.D.; SCHINGOETHE, D.J. Heat-treated soybeans for lactating cows, Journal of Dairy Science, v.64, n.7, p.1579-1585, 1981.

MILTON, C.T.; BRANDT Jr., R.T.; TITGEMEYER, E.C. Urea in dry-rolled corn diets: finishing steer performance, nutrient digestion, and microbial protein production. Journal of Animal Science, v.75, n.5, p.1415-1424, 1997.

NATIONAL RESEARCH COUNCIL. Ruminant nitrogen usage. Washington: National Academy Press, 1985. 138p.

NATIONAL RESEARCH COUNCIL. Nutrient requirements of dairy cattle. 7 . ed. Washington: National Academy Press, 2001. 408p.

NOCEK, J.E.; TAMMINGA, S. Site of digestion of starch in the gastrointestinal tract of dairy cows and its effect on milk yield and composition. Journal of Dairy Science, v.74, n.10, p.3598-3629, 1991.

NOCEK, J.E.; HART, S.P.; POLAN, C.E. Rumen ammonia concentration as influenced by storage time, freezing and thawing, acid preservative, and method of ammonia determination. Journal of Dairy Science, v.70, n.3, p.601-607, 1987.

NORLAN, J.V. Quantitative models of nitrogen metabolism in sheep. In: MacDONALD, I.W.; WANER, A.C.I. (Ed.). Digestion and metabolism in the ruminant. Armidale: University of New England, 1975. 602p.

OWENS, F.N.; GOETSCH, A.L. Digesta passage and microbial protein synthesis. In: MILLIGAN, L.P.; GROVUM, W.L.; DOBSON, A. (Ed.) Control of digestation and metabolism in ruminants. Englewood Cliffs: Prentice Hall, 1986. p.196-223.

OWENS, F.N.; ZINN, R.A.; KIM, Y.K. Limits to starch digestion in the ruminant small intestine. Journal of Animal Science, v.63, n.5, p.1634-1648, 1986.

PALMQUIST, D.L.; CONRAD, H.R. Origin of plasma fatty acids in lactating cows fed high grain or high fat diets. Journal of Dairy Science, v.54, n.7, p.1025-1033, 1971. 
PETIT, H.V.; RIOUX, R.; OUELLET, D.R. Milk production and intake of lactating cows fed raw or extruded peas. Journal of Dairy Science, v.80, n.12, p.3377-3385, 1997.

PIRES, A.V.; EASTRIDGE, M.L.; FIRKINS, J.L.; LIN, Y.C. Effects of heat treatment and physical processig of cottonseed on nutrient digestibility and production performance by lactating cows. Journal of Dairy Science, v.80, n.8, p.1685-1694, 1997.

POORE, M.H.; MOORE, J.A.; SWINGLE, R.S.; ECK, T.P.; BROW, W.H. Wheat straw or alfalfa hay in diets with $30 \%$ neutral detergent fiber for lactating Holstein cows. Journal of Dairy Science, v.74, n. 9, p.3152-3159, 1991.

PRIGGE, E.C.; VARGA, G.A.; VICINI, J.L.; REID, R.L.. Comparison of ytterbium chloride and chromium sesquioxide as fecal indicators. Journal of Animal Science, vol.53, n.6, p.1629-1633, 1981.

REDDY, P.V.; MORRILL, J.L.; NAGARAJA, T.G. Release of free fatty acids from raw or processed soybeans and subsequent effects on fiber digestibilities, Journal of Dairy Science, v.77, n.11, p.3410-3416, 1994.

ROONEY, L.W.; PFLUGFELDER, R.L. Factors affecting starch digestibility with special emphasis on sorghum and corn. Journal of Animal Science, v.63, n.5, p.1607$1623,1986$.

RULQUIN, H.; VERITE, R. Amino acid nutrition of dairy cows: productive effects and animal requirements. In: GARNSWORTHY, P.C.; COLE, D.J.A. (Ed). Recent advances in animal nutrition. Nottingham University Press, 1993. p.55.

RUSSELL, J.B.; O'CONNOR, J.D.; FOX, D.J.; VAN SOEST, P.J.; SNIFFEN, C.J. A net carbohydrate and protein system for evaluating cattle diets: I Ruminal fermentation. Journal Animal Science, v.70, n.1, p.3551-3561, 1992.

SANTOS, F.A.P. Effect of sorghum grain processing and protein source on performance and nutrient utilization by lactating dairy cows. Tucson, 1996. 140p. Tese (PhD) - University of Arizona.

SANTOS, F.A.P. Efeito de fontes protéicas e processamento de grãos no desempenho de vacas de leite e digestibilidade dos nutrientes. Piracicaba, 1998. 105p. Tese (Livre-Docência) - Escola Superior de Agricultura "Luiz de Queiroz", Universidade de São Paulo. 
SANTOS, F.A.P.; SANTOS, J.E.P.; THEURER, C.B.; HUBER, J.T. Effects of rumenundegradable protein on dairy cow performance: a 12-year literature review. Journal of Dairy Science, v.81, n.12, p.3182-3213, 1998.

SANTOS, F.P.; HUBER, J.T. Quality of bypass proteins fed to high-producing cows is important. Feedstuffs, v.68, n.34, p.12-15, 1996.

SANTOS, J.E.P ;. HUBER, J.T; THEURER, C.B.;. NUSSIO, L.G; TARAZON, M.; SANTOS, F.A.P. Response of lactating dairy cows to steam-flaked sorghum, steamflaked corn, or steam-rolled corn and protein sources of differing degradability. Journal of Dairy Science, v.82, n.4, p.728-737, 1999.

SAS INSTITUTE. SASISTAT: user's guide, version 6. Cary, 1990. 2v.

SATTER, L.D.; SLYTER, L.L. Effect of ammonia concentration on rumen microbial protein production in vitro. British Journal of Nutrition, v.32, n.2, p.199-208, 1974.

SCHWAB, C.G. Optimizing amino acid nutrition for optimum yields of milk and milk protein. In: SOUTHWEST NUTRITION AND MANAGEMENT CONFERENCE, Tucson, 1994. Proceedings. Tucson: University of Arizona, 1994. p.114-129.

SCOTT, T.A.; COMBS, D.K.; GRUMMER, R.R. Effects of roasting, extrusion, and particle size on the feeding value of soybeans for dairy cows. Journal of Dairy Science, v.74, n.8, p.2555-2562, 1991.

SHABI, Z.; ARIELI, A.; BRUCKENTAL, I.; AHARONI, Y.; ZAMWEL, S.; BOR, A.; TAGARI, $H$. Effect of the synchronization of the degradation of dietary crude protein and organic matter and feeding frequency on ruminal fermentation and flow of digesta in the abomasum of dairy cows. Journal of Dairy Science, v.81, n.7, p. 1991-2000, 1998.

SLOAN, B.K.; GARTHWAITE, B.D.; SCHWAB, G.S. Fine-tuning sub-model may optimize production. Feedstuffs, v.71, n.9, p.11-15, 1999.

SNIFFEN, C.J.; ROBINSON, P.H. Protein and fiber digestion, passage, and utilization in lactating cows. Microbial growth and flow as influenced by dietary manipulations. Journal of Dairy Science, v.70, n.2, p.425-441, 1987.

SOCHA, M.T.; SATTER, L.D. Feeding of heat-processed whole soybeans to primiparous and multiparous cows. Journal of Dairy Science, v.74, suppl.1, p.251, 1991. 
SOLOMON, R.; CHASE, L.E; BEN-GHEDALIA, D.; BAUMAN, D.E. The effect of nonstructural carbohydrate and addition of full fat extruded soybeans on the concentration of conjugated linoleic acid in the milk fat of dairy cows. Journal of Dairy Science, v.83, n.6, p.1322-1329, 2000.

THEURER, C.B.; HUBER, J.T.; CHEN, K.H.; SWINGLE, R.S. Update on grain processing research in lactating cows. In: SOUTHWEST NUTRITION AND MANAGEMENT CONFERENCE, Tucson, 1993. Proceedings. Tucson: University of Arizona, 1993. p.70-77.

THEURER, C.B.; HUBER, J.T.; DELGADO-ELORDUY, A.; WANDERLEY, R. Invited review: Summary of steam-flaking corn or sorghum grain for lactating dairy cows. Journal of Dairy Science, v.82, n.9, p.1950-1959, 1999.

THEURER, C.B.; HUBER, J.T.; SANTOS, F.A.P. Feeding and managing for maximal milk protein. In: In: SOUTHWEST NUTRITION AND MANAGEMENT CONFERENCE, Tucson, 1995. Proceedings. Tucson: University of Arizona, 1995. p. 59-67.

TICE, E.M.; EASTRIDGE, M.L.; FIRKINS, J.L. Raw soybeans and roasted soybeans of different particle sizes. 1. Digestibility and utilization by lactating cows. Journal of Dairy Science, v.76, p.224-229, 1993.

VAN SOEST, P.J. Nutrition ecology of the ruminants. 2. ed. Ithaca: Cornell University Press, 1994. $476 \mathrm{p}$.

VAN SOEST, P.J.; ROBERTSON, J.B.; LEWIS, B.A.. Methods for dietary fiber, neutral detergent fiber, and nonstarch polysaccharides in relation to animal nutrition. Journal of Dairy Science, v.74, n.10, p.3583-3596, 1991.

VIRTANEN, A.I. Milk production of cows on protein-free feeds. Science, v.153, n.744, p. 1603-1616, 1966.

VOSS, V.L.; STEHR, D.; SATTER, L.D.; BRODERICK, G.A. Feeding lactating dairy cows proteins resistant to ruminal degradation. Journal of Dairy Science, v.71, n.9, p. $2428-2439,1988$

YANG, W.Z.; BEAUCHEMIN, K.A.; RODE, L.M. Effects of barley grain processing on extent of digestion and milk production of lactating cows. Journal of Dairy Science, v.83, n.3, p.554-568, 2000. 
YOKOYAMA, M.T.; JOHNSON, K.A. Microbiology of the rumen and intestine. In: CHURCH, D.C. (Ed.) The ruminant animal: Digestive physiology and nutrition. Englewood Cliffs: Prentice-Hall, 1988. cap.7, p.125-144.

YU, P.; HUBER, J.T.; THEURER, C.B.; CHEN, K.H.; NUSSIO, L.G.; WU, Z. Effect of steam-flaked or steam-rolled corn with or without Aspergillus oryzae in the diet on performance of dairy cows fed during hot weather. Journal of Dairy Science, v.80, n.12, p.3293-3297. 1997.

ZINN, R.A.; OWENS, F.N. A rapid procedure for purine measurement and its use for estimating net ruminal protein synthesis. Canadian Journal of Animal Science, v.66, n.1, p.157-166, 1986. 